\title{
COO-4051-29
}

Division of Engineering BROWN UNIVERSITY PROVIDENCE, R. I.

\section{A SOURCEBOOK ON THE PRODUCTION OF} ELECTRICITY FROM GEOTHERMAL ENERGY

CHAPTER 2 (DRAFT). RESOURCE CHARACTERISTICS: RESERVOIRS, WELLHEADS AND DELIVERY SYSTEMS

PART 3. ANALYSIS OF THE FLOW IN THE RESERVOIR - WELL SYSTEM

D. J. Ryley

\section{U. S. Department of Energy Contract EY-76-S-02-4051.A001}

Report No. CATMEC/22

June 1978 


\section{DISCLAIMER}

This report was prepared as an account of work sponsored by an agency of the United States Government. Neither the United States Government nor any agency Thereof, nor any of their employees, makes any warranty, express or implied, or assumes any legal liability or responsibility for the accuracy, completeness, or usefulness of any information, apparatus, product, or process disclosed, or represents that its use would not infringe privately owned rights. Reference herein to any specific commercial product, process, or service by trade name, trademark, manufacturer, or otherwise does not necessarily constitute or imply its endorsement, recommendation, or favoring by the United States Government or any agency thereof. The views and opinions of authors expressed herein do not necessarily state or reflect those of the United States Government or any agency thereof. 


\section{DISCLAIMER}

Portions of this document may be illegible in electronic image products. Images are produced from the best available original document. 


\section{NOTICE}

Th1s report was prepared as an account of work sponsored by the United States Government. NeIther the United States nor the United States Department of Energy, nor any of their employees, nor any of thelr contractors, subcontractors, or their employees, makes any warranty, express or Implied, or assumes any legal liability or responsibility for the accuracy, completeness, or usefulness of any information, apparatus, product or process disclosed or represents that its use would not infringe privately owned rights.

\section{NOTICE}

Reference to a company or product name does not imply approval or recommendation of the product by Brown University or the United States Department of Energy to the exclusion of others that may be suitable. 
A Sourcebook on the Production of Electricity from Geothermal Energy

Chapter 2, Part 3

ANALYSIS OF THE FLOW IN THE RESERVOIR-WELL SYSTEM

\author{
June 1978 \\ Performed under \\ Department of Energy \\ Division of Geothermal Energy
}

Contract No. EY-76-S-02-4051.A001

Contract No. EY-76-5-02-4051.A001 
"...Sir, thou hast nothing to draw with and the well is deep..."

$$
\text { John, 4-11 }
$$




\section{PREFACE}

This report is a preliminary version of material assembled for insertion in the Sourcebook on the Production of Electricity from Geothermal Energy currently being composed under ERDA (nOW DOE) Contract EY-76-S-02-4051.A001.

Chapter 2 of the Sourcebook is headed "Resource Characteristics: Reservoirs, Wellheads and Delivery Systems" and is to be divided into six sections. Sections 1 and 2 have already been issued in combined form as CATMEC/16 which is a Draft Report entitled An Introduction to the Geology and Geophysics of Thermal Areas.

The flow of geofluids in geothermal wells has been competently treated in recently published papers by several investigators. One defect, however, has been common to all the papers reviewed by the present writer, namely, that the investigator has addressed a particular well, or type or phenomenon and has selected only those aspects of theory that he has needed to explain his findings. The published material tends to be comect, but incomplete and disconnected. An attempt has been made here to develop the theory of the well in an ordered stepwise manner beginning from the three basic "continuities" and introducing each new idea systematically. It is a formal textbook approach.

This report is not directed towards research workers and exports except insofar as it may encourage them to review critically their basic assumptions and to present tidily their arguments. The writer has avoided entering areas of dispute. Most issues currently in dispute cannot be resolved solely in terms of theory and current technology. However tempting speculation may be many devices will have to be built and tried out and their economic status appraised. 
It would have been satisfying if this report could have been terminated by a definitive section on two-phase flow patterns, the conditions governing their mutual transition and the friction pressure losses associated with each type. Unfortunately, as every student of two-phase flow knows, this knowledge has long been denied to us despite strenuous effort.

In returning to the subject of geothermal well analysis after a long absence I have been grateful for the stimulation received by reading Dr. D. G. Elliot's detailed contributions in CATMEC Reports, Numbers 3, 5 and 10.

D. J. Ryley

Division of Engineering

Brown University

Providence, RI 02912

June, 1978 


\section{CONTENTS}

NOTATION

$\underline{\text { Page }}$

2.6.1 FLOW IN A WELL PIPE

2.6.1.1 The Continuity Equations for Vertical Flow in a Pipe

2.6.1.2 Artesian Flow in Wells

2.6.1.3 Phase Change within the Well

2.6.1.4 The Non-Adiabatic Well

2.6.1.5 The Boiling Point - Depth Curve

2.6.1.6 The Pumped Well

2.6.2 CHARACTERISTICS OF THE COMBINED WELL-RESERVOIR SYSTEM

2.6.2.1 Single-Phase (Liquid) Self-Flowing System

2.6.2.2 Wellhead Pressure - Flowrate Characteristic for Self Flowing Liquid Well (Example)

2.6.2.3 Single-Phase (Liquid) Pumped System

2.6.2.4 Two-Phase Self-Flowing Well

2.6.2.5 Wellhead Characteristics for a Self-Flowing Flashing Well

2.6.2.6 The Stepped-Diameter Well (Example)

2.6.2.7 Variation in Depth to Flash Level in Self-Flowing Well

2.6.2.8 Choked Flow

2.6.2.9 Estimation of the Mass Flowrate from Wells

2.6.3 PATTERNS OF PHASE ASSOCIATION IN VERTICAL TWO-PHASE FLOW

2.6.3.1. Flow Patterns in Vertical Flow

2.6.3.2 Transition of Flow Pattern

2.6.4 THERMODYNAMIC AVAILABILITY IN GEOTHERMAL SYSTEMS

2.6.4.1 Availability Analysis of the Well Pipe

2.6.4.2 Availability Analysis of the Well Pipe - Power Plant System

2.6.4.3 Utilization Factor.

2.6.4.4 The Dead State 


\section{FIGURES}

FIG. NO: -

1. ANALYSIS OF VERTICAL FLOW IN A GEOTHERMAL WELL

2. TEMPERATURE, HYDROSTATIC PRESSURE AND LIQUID DENSITY FOR A

PURE WATER COLUMN SATURATED AT ALL LEVELS

3. TEMPERATURE VS. DEPTH: MISCELLANEOUS CURVES IN EARTH AND IN BRINE

4. WELL PUMPING BY COMPRESSED GAS

5. THE WELL AND ASSOCIATED RESERVOIR (a) No pump (b) Well pumped

6. FLOW RATE, WELLHEAD PRESSURE AND DRAWDOWN FOR SELF-FLOWING WELL

7. VISCOSITY OF PURE SATURATED WATER

8. THE SELF-FLOWING FLASHING WELL (a) Diagram showing general notation

(b) Notation at the wellhead where the equivalent filaments cross the well exit

9. THE SELF-FLOWING FLASHING WELL: MISCELLANEOUS CURVES

10. THE SELF-FLOWING FLASHING WELL: MISCELLANEOUS CURVES

11. DEPTH TO FLASH LEVEL IN SELF-FLOWING WELL (a) Pressure-depth curves (b) Miscellaneous curves

12. PRINCIPAL FLOW PATTERNS IN VERTICAL TWO-PHASE FLOW

13. DIAGRAM FOR ILLUSTRATING THE CONCEPT OF AVAILABILITY

14. VARIATION OF AVAILABLE ENERGY WITH HEAT REJECTION TEMPERATURE FROM ENERGY SOURCES AT GIVEN INITIAL CONDITIONS 


\section{NOTATION}

A

Pipe Area

$m^{2}$

Constant

B

Constant

C

Loss coefficient for sudden expansion

$D=2 x$

Pipe diameter

m

F

Driction force

N

Mass flux

$\mathrm{kg} / \mathrm{m}^{2} \mathrm{~s}$

$\mathrm{K}$

Permeability

$\operatorname{darcy}\left(m^{2}\right)$

$\mathbf{L}$

Height of aquifer

m

H Hach number

P

$\dot{Q}$

Pressure

$\mathrm{kPa}, \mathrm{HPa}$

Rate of heat transfer

$\mathrm{kJ} / \mathrm{s}(\mathrm{kW})$

R

Characteristic gas constant

$\mathrm{kJ} / \mathrm{kg}{ }^{\circ} \mathrm{K}$

Reservoir radius

m

$\mathbf{T}$

Temperature

${ }^{\circ} \mathrm{C},{ }^{\circ} \mathrm{K}$

Velocity

$\mathrm{m} / \mathrm{s}$

Rate of work transfer

$\mathrm{kJ} / \mathrm{s}(\mathrm{kW})$

Maximum available work

$\mathrm{kJ} / \mathrm{kg}$

Martinel11 parameter

\begin{tabular}{|c|c|c|}
\hline$a, b, c, d, e$ & Coefficlents in equation (21) & \\
\hline$b$ & Specific avallability & $\mathrm{kJ} / \mathrm{kg}$ \\
\hline f & Friction factor (coefficlent) & \\
\hline $\mathbf{g}$ & Gravitational constant & $\mathrm{m} / \mathrm{s}^{2}$ \\
\hline h & Specific enthalpy & $\mathrm{kJ} / \mathrm{kg}$ \\
\hline k & SIip ratio & \\
\hline
\end{tabular}




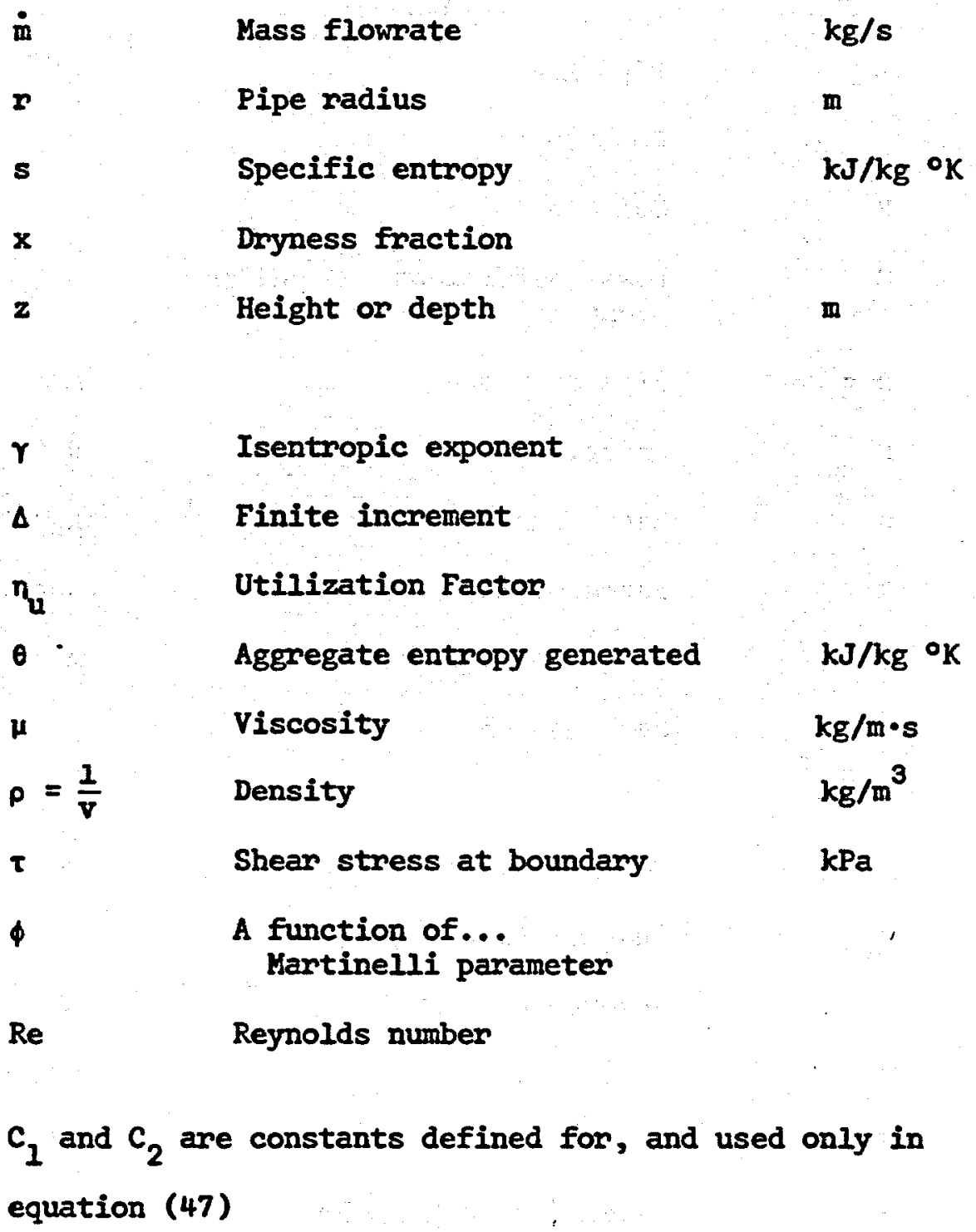

SUBSCRIPTS

1

Well bottom (inlet)

2

Well bead (exit)

3

Remote reservoir 


$\begin{array}{ll}\text { a } & \text { Acoustic } \\ \text { c } & \text { Critical } \\ \text { f } & \text { Saturated liquid } \\ \text { g } & \text { Saturated vapor } \\ \text { fg } & \text { Liquid-vapor change } \\ \text { p } & \text { Pump } \\ \text { o } & \text { Dead State } \\ \text { F } & \text { Stagnation } \\ \text { H } & \text { Depth to flash level } \\ \text { L } & \text { Liquid column above pump } \\ \text { S } & \text { Liquid column below pump } \\ \text { W } & \text { Single-phase section, saturation } \\ \text { SP } & \text { Liquid column } \\ \text { TP } & \text { Single-phase } \\ & \text { Two-phase }\end{array}$

A bar ( ) above a symbol denotes a mean value. A dot $\left({ }^{\circ}\right)$ above a symbol denotes a time rate. 


\subsubsection{FLOW IN A WELL PIPE}

In order to analyze the upward flow of fluid in a well we consider a thermodynamic system the side boundaries of which are coincident with the boundaries swept by the fluid. The boundaries across which occur the liquid inflow and outflow may be defined as required. We may choose to include the reservoir and/or the power plant within the system, but for the present we are concerned only with the liquid column within the well pipe. It is convenient therefore to terminate the system flow boundaries at the well pipe entrance and exit.

Whatever may be the nature and extent of the energy transfers across the system boundary or within it there will always exist continuity of mass flow, of energy and of momentum provided all comditions are established and steady, i.e., no transients occur. This applies equally for single- or two-phase flow and is independent, in the latter case, of the existence or absence of "slip" between the phases.

\subsubsection{The Continuity Equations for Vertical Flow in a Pipe}

The great majority of geothermal well bores are vertical or very mearly so and the vertical well will be treated here. For a well with an inclined section it is a simple matter to insert an angle of inclination in the potential energy term (Gould, 1974).

An element of the flow, $A B C D$, is shown in Fig. 1. The symbols have their usual meanings. In the most general case there are elements of heat and work

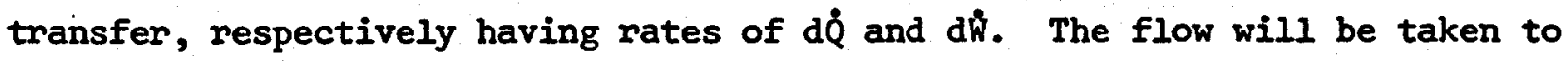
be two-phase and homogeneous. An element having phase slip can readily be analyzed [Ryley, 1965; Fukuda, et al., 1975] but introduces complications.

For mass continuity,

$$
\dot{\mathrm{m}}=\rho_{\mathrm{TP}} V_{\mathrm{A}}
$$


For energy continuity,

$$
d \dot{Q}-d \dot{W}=\dot{m}\left[d h+d\left(\frac{v^{2}}{2}\right)+g d z\right]
$$

For momentum continuity it is necessary to recognize the friction force arising on the swept boundary which is denoted by $\mathrm{dF}$ for the element as a whole. The momentum equation then becomes

$$
-d P=\rho_{T P} V d V+\frac{d F}{A}+\rho_{T P} g d z
$$

Integrating equation (2) over the whole height of the pipe,

$$
\begin{aligned}
& \text { - } \int_{z_{1}}^{z_{2} d \dot{d}}-\int_{z_{1}}^{z_{2} d \dot{w}}=\dot{m}\left[\int_{h_{1}}^{h_{2}} d h+\int_{v_{1}}^{v_{2}} d\left(\frac{v^{2}}{2}\right)+g \int_{z_{1}}^{z_{2}}\right] \\
& =\dot{m}\left[\left(h_{2}-h_{1}\right)+\frac{1}{2}\left(v_{2}^{2}-v_{1}^{2}\right)+g\left(z_{2}-z_{1}\right)\right] \\
& =\dot{m}\left[h_{02}-h_{01}+g\left(z_{2}^{\left.\left.-z_{1}\right)\right]}\right.\right.
\end{aligned}
$$

The terms in $\dot{Q}$ and $\dot{W}$ cannot be integrated without a knowledge of the functions $\dot{Q}=\dot{Q}(z)$ and $\dot{W}=\dot{W}(z)$. However, in the practical well $\dot{W}$ will only occur if a downhole pump wherever located accepts an energy input from outside the well. The term in $Q$ is frequently taken to be zero either because heat gains and losses balance or more usually because $\dot{Q}$ is small compared with

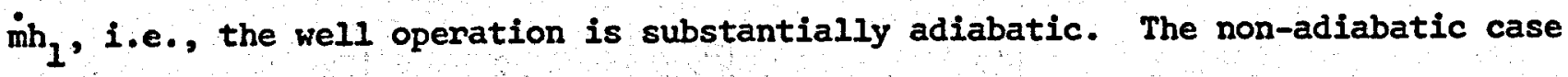
will be considered in Section 2.6.1.4.

With these simplifications, equation (4a) reduces to

$$
h_{1}+\frac{v_{1}^{2}}{2}=h_{2}+\frac{v_{2}^{2}}{2}+g\left(z_{1}-z_{2}\right)
$$

In a two-phase mixture with slip these quantities must be interpreted thus: $h$ is the sum of the enthalpies of the saturated liquid and the saturated 
vapor respectively which together comprise unit mass crossing a flow section at $z_{1}$ or $z_{2} \cdot v^{2} / 2$ is likewrise the combined kinetic energy.

The kinetic energy terms are usually small in comparison with the remaining terms, or $v_{1} \simeq v_{2}$, and equation (5) may assume the frequently-used approximate form

$$
h_{1}=h_{2}+g\left(z_{2}-z_{1}\right)
$$

Even for a deep low-temperature well the potential energy term $g\left(z_{2}-z_{1}\right)$ never exceeds about $5 \%$ of the enthalpy $h$ and hence for rough work equation (6) is sometimes abbreviated to

$$
h_{1}=h_{2}
$$

Considering now the momentum equation ( 3 ) and integrating we obtain

$$
-\int_{P_{1}}^{P_{2}} d P=\int_{V_{1}}^{V_{2}} \rho_{T P} V d V+\frac{1}{A} \int_{z_{1}}^{z_{2}} d F+g \int_{z_{1}}^{z_{2}} \rho_{T P} d z
$$

The density $\rho_{T P}^{*}$ and the velocity $V$ are both functions of $z$. If $\tau$ is the shear stress at the boundary and $f_{\mathrm{TP}}^{*}$ the two-phase coefficient of friction,

$$
\mathrm{dF}=i \pi \mathrm{Ddz}=\mathrm{f}_{\mathrm{TP}} \frac{P_{\mathrm{TP}}}{2} \pi \mathrm{DV} \mathrm{V}^{2} \mathrm{dz}
$$

Equation (8) may now be written

$$
P_{1}-P_{2}=\int_{V_{1}}^{V_{2}} \rho_{T P} V d V+\frac{2}{D} \int_{z_{1}}^{z_{2}} f_{T P} \rho_{T P} V^{2} d z+g \int_{z_{1}}^{z_{2}} \rho_{T P} d z
$$

\footnotetext{
The two-phase density $\rho_{\text {TP }}$ and the two phase friction factor $f_{\text {TP }}$ will be discussed later. It is here sufficient to notice that each quantity is quality(i.e., dryness fraction-) dependent and its magnitude may be written in terms of the quality so as to embrace the complete quality range from saturated liquid to saturated vapor.
} 
If the liquid phase only is present at all levels in the well and its mean density if $\bar{\rho}_{W}$ the velocity $V$ is substantially constant if the bore diameter $D$ does not change. Equation (10) may then be adjusted to give

$$
\frac{P_{1}-P_{2}}{\bar{P}_{W}}=\frac{2}{D} f_{W} V^{2}\left(z_{2}-z_{1}\right)+g\left(z_{2}-z_{1}\right)
$$

where $f_{W}$ is the friction factor for liquid alone assumed constant. Equation (il) is the Bemoulli equation for an incompressible flow with friction.

\subsubsection{Artesian Flow in Wells}

A well may or may not be self-flowing depending upon whether the bottomhole pressure exceeds or is less than the accompanying hydrostatic pressure due to the overlying fluid column in the pipe. The excess pressure to promote self-flow will arise as a consequence of one or both of two factors which may act singly or together; the height of the external water table and the mean density of the geofluid lying between the water table and the well base. Thus considering Fig. 1 let the height of the well column be $z_{W}=z_{2}-z_{1}$ and let the column mean density be $\bar{p}$ irrespective of how this density is attained by variations in a single- or two-phase mixture. Let the elevation of the water table be $z_{T}$ (shown conventionally with $z_{T}>z_{W}$ ) and let the mean external liquid density be $P_{T}$. An imaginary column EF of liquid of cross-sectional area $A$ equal to that of the well may be assumed connected to the well inlet as shown. Considering the well inlet, Section 1, the upward pressure due to the external column EF is

$$
P_{1}=\rho_{T} \& z_{T}
$$

The closed-in pressure at the wellhead, Section 2 , is less than $P_{1}$ by that generated by the well column, i.e., 


$$
\begin{aligned}
P_{2} & =\rho_{T} g z_{T}-\bar{\rho}_{g z_{W}} \\
& =g\left(\rho_{T} z_{T}-\bar{\rho} z_{W}\right)
\end{aligned}
$$

The artesian action is governed by the quantity $\left(\rho_{T} z_{T}-\bar{p} z_{W}\right)$. If $\left(\rho_{T_{T}} z_{T}-\bar{\rho} z_{W}\right)>0$ the well will flow spontaneously. It is not necessary for the water table to be above the well exit for artesian action; it may be caused by density inequality. If $\left(\rho_{\mathrm{T}} z_{\mathrm{T}}-\bar{\rho}_{\mathrm{W}}^{-}\right)>0$ then the well will flow upon opening the wellhead valye, the pressure $P_{2}$ will fall to compensate for the pressure losses associated with pipe friction and the generation of fluid kinetic energy in accordance with equation (10). The base pressure $P_{1}$ will also fall by an increment governed by the characteristics of the reservoir. In many wells the pressure $P_{1}$ is substantially equal to the hydrostatic pressure of the well column, i.e.,

$$
P_{1}=\overline{\rho g z_{W}}=\rho_{T} g z_{T}
$$

hence the well fills but does not flow.

In the above treatment it was sufficient to define the height and mean density of the column EF. Both of these may depend upon a variety of external physical structures and conditions [Nathenson, 1974; Yuhara, 1970; Yuhara and Tomosada, 1965].

\subsubsection{Phase Change Within the Well}

A hot liquid with a free surface will yaporize when the vapor pressure at the interface falls below the saturation value corresponding to the liquid temperature. However, when hot liquid is rising in a well no free surface is available when saturation conditions are reached and a temporary metastable state ensues with the liquid becoming superheated. The duration of metastability is usually brief and is substantially terminated by the onset of vapor nucleation 
within the body of the liquid and at its boundaries. Thereafter thermal equilibrium will be continuously approached but never fully reached. No satisfactory criteria exist for calculating phase change rates in this context and as the residual themal disequilibrium is always likely to be small it is conventional (and acceptable) to assume thermal equilibrium at all levels' within the well including the two-phase vapor/liquid region. Thus above the flashing level vaporization will continue with the mass flow dryness fraction increasing continuously until the wellhead is reached.

In the event that the flow is adiabatic $(Q=0)$ and quasi-static and the entry temperature $T_{1}$ is known, the depth $z_{F}$ at which flashing will occur can be calculated because $T_{1}$ defines the flashing pressure, $P_{S I}$. Provided, therefore, that $d V=0$ and no pump is placed after Section 1 (i.e., d $\dot{W}=0)$ the momentum continuity equation between Section 1 and the flash level reduces to

$$
P_{S 1}=P_{I}-\bar{p}_{W} \cdot g\left(z_{W}-z_{F}\right)
$$

where $\bar{\rho}_{W}$ is the mean liquid density for the part column below the flash level.

Equation (15) may be rearranged, with substitution from equation (14) to give

$$
z_{F}=z_{W}-\left(\frac{\rho_{T} z_{T}}{\bar{\rho}_{W}}-\frac{P_{S I}}{\bar{\rho}_{W} g}\right)
$$

In the event that $z_{T}=z_{W}$ equation (16) reduces to

$$
z_{F}=\frac{P_{S 1}}{\bar{\rho}_{W}^{\prime} g}-z_{W}\left(\frac{p_{T}}{\bar{P}_{W}^{\prime}}-1\right)
$$

Some interesting implications of this expression are explored by Elliott [1977]. The subject of flash level is considered further in Section 2.6.2.7. 


\subsubsection{The Non-Adiabatic Well}

As stated above it is usual to assume that for the entire vertical bore

$\int_{z_{1}}^{z_{2}} d Q^{\prime}=0$, but it is readily seen that conditions could arise in which this was not the case. Thus the ascending hot geofluid might traverse an aquifer of significant depth conveying a colder fluid, or a dry local intrusion at a temperature exceeding that of the lower formation reservoir being exploited.

In this event it may become necessary to resort to a finite interval solution, for which the equations (2) and (10) would take, for unit mass flowrate, the forms

$$
\Delta \dot{Q}-\Delta \dot{W}=\Delta h+\Delta\left(\frac{v^{2}}{2}\right)+g \Delta z
$$

and

$$
-\Delta P=\rho V \Delta V+\frac{2}{D} f_{\rho} V^{2} \Delta z+g \rho \Delta z
$$

where $\Delta z$ is a finite depth interval of arbitrary magnitude and the friction coefficient $f$ and density $p$ are assigned appropriate values.

Mass continuity remains as

$$
\dot{\mathrm{n}}=\mathrm{A \rho V}
$$

To solve the coupled equations (18) through (20) it is usual to start calculations from the well inlet. It is necessary to know $P_{1}, T_{1}, V_{1}$ and $A$; $h_{1}=h_{1}\left(T_{1}\right)$ and $\rho_{1}=\rho_{1}\left(P_{1}, T_{1}\right)$. It is thereafter necessary to know, for each depth increment $\Delta z$, the values of $\Delta \dot{Q}, \Delta \dot{W}$ and $f_{T P}$. The work transfer term $\Delta \dot{W}$ will be zero except only at the location of a pump, if any. A given calculation sequence may be specific to the value of $\dot{m}$ because mass flowrate is functionally related to the drawdown and hence to $P_{1}$.

The calculation cannot proceed into the two-phase flow region unless values can be assigned to $f$. This raises the question of the flow pattern sequence and the locations within the well at which transitions of pattern occur. 
The above procedure may be varied in detail and computer solutions are usually sought [Nathenson, 1974; Austin, 1977; Elliot, 1975; Gould, 1974].

The object of a stepwise solution may be to establish certain inlet or other conditions which will promote a defined value of a property elsewhere (e.g., defined temperature at the wellhead). In such an event a guessed property may be used as input and the final result obtained by using iteration for progressive refinement.

\subsubsection{The Boiling Point/Depth Curve}

It is instructive to consider a non-flowing well in which the liquid is at boiling temperature throughout the column height. In this case if a diametral plane at a given depth in the liquid is considered there will be a single value of hydrostatic pressure due to the overlying column and a corresponding value of boiling point temperature. The variation of boiling temperature with depth for a column of pure water saturated at all depths is shown in Fig. 2 together with the pressure and density. It is seen that the temperature gradient is high at shallow levels but declines at deeper levels, also that the density decreases continuously towards the wellbottom. Any column of this type is thus in convective disequilibrium as is any column in which fluid of high density overlies fluid of lower density, hence most non-flowing columns have Internal convection currents generated by the earth's temperature gradient (See Section 2.2.2). Owing to the convective overtumn and the low temperature/ depth gradient at great depths there is virtually a constant temperature in this locality, frequently referred to as the "base temperature."

The boiling point/depth curve is modified for a liquid column containing dissolved salts. Fig. 3 shows a family of such curves for water with various sodium chloride concentrations. 
The boiling point/depth curve for pure water was calculated for a standard atmospheric pressure over the free surface, using finite depth intervals and tabulated thermodynamic properties. Down to a depth $z$ of $2 \mathrm{~km}$ the temperature/ depth relation is given to within $\pm 1^{\circ} \mathrm{C}$ by the relation

$$
T=a z^{4}+b z^{3}+c z^{2}+d z+e
$$

Where $T$ is in ${ }^{\circ} \mathrm{C}$ and $\mathrm{z}$ is in meters and the coefficients are

$$
\begin{aligned}
& a=-6.26862 \times 10^{-9}{ }^{\circ} \mathrm{C} / \mathrm{m}^{4} \\
& b=1.97471 \times 10^{-5}{ }^{\circ} \mathrm{C} / \mathrm{m}^{3} \\
& c=-1.54359 \times 10^{-2}{ }^{\circ} \mathrm{C} / \mathrm{m}^{2} \\
& d=2.15416{ }^{\circ} \mathrm{C} / \mathrm{m} \\
& e=100.0{ }^{\circ} \mathrm{C}
\end{aligned}
$$

An alternative expression has been given by James [1970]. After conversion for depths in meters it reads

$$
T=69.56 z^{0.2085}
$$

where $T$ is ${ }^{\circ} \mathrm{C}$ and $\mathrm{z}$ is in meters. The water surface temperature is assumed to be $100^{\circ} \mathrm{C}$ and the equation applies over the depth range $\mathrm{z}=30 \mathrm{~m}$ to $3050 \mathrm{~m}$.

Temperature/depth curves may be taken in a well during the process of drilling, when the completed well is filled with water and has remained static for a longer or shorter period, or while the well is flowing. Temperatures taken during drilling may be misleading and have been discussed in Section 2.2.2. Most measurements are made on static closed-in wells [e.g. J. H. Smith, 1970] and the temperature/depth profile tends to lie within the boiling point/depth curve. Some explanations of the shapes assumed by temperature/depth curves are given by Vakin, et al. [1970].

Fig. 3 displays two anomalous temperature/depth curves taken with closed wells. That taken at Wairakei Hole 18 was taken after an elapsed time of 101 days in geofluid having dissolved solids of $0.38 \%$ by weight and it reflects 
the general characteristics of temperature gradients in this area. There is a rapid increase in temperature down to the base of the confining sandstone where the temperature exceeds the boiling point/depth value. The other curve was taken at well T7 at The Geysers after a lapse of 60 days. The constant value of temperature from a depth of 40 to $130 \mathrm{~m}$ indicates the existence of vapor which pressure measurements show to be saturated.

\subsubsection{The Pumped Well}

For reasons discussed below it may be necessary to provide a well with a pump. It has been pointed out that there are no thermodynamic criteria involved in choosing the pump location, but several other factors that must be considered include the following.

(1) The pump must be located at a depth sufficient to avoid cavitation at all loads. It will be shown in section 2.6 .2 .7 that as the mass flow from a well increases the depth to the flash level falls, and the pump location must ensure freedom from cavitation on full load.

(2) Whatever type of pump is employed it will have service connections with the surface and the cost of these will increase with pump depth.

(3) Removal of the pump for servicing will increase in cost and in time as the pump depth increases.

A well may be pumped for one or more of the following reasons:

(a) To promote a flow in the absence of artesian action.

(b) To increase the flowrate in order to augment the well capacity. In this case it is also necessary to take account of the liquid supply to the wellbottom to ensure its adequacy. The drawdown characteristics of the reservoir must be examined lest the pump defeat its own pumpose. This subject will be considered further in Section 2.6.2. 
(c) To suppress flashing within the wellbore. Boiling may cause the precipation of solids which adhere to the bore and cause a progressive restriction on the mass flow. Suppression of flashing may also prevent limitation of the mass flowrate arising from vapor or vaporliquid choking at a later stage in the flow.

It is convenient to consider these cases separately.

(1) Suppose the well is at rest and that the external conditions of water table level and ground water density are such that the well level is in equilibrium at a depth $z_{E}$ below the sumface. Then for a frictionless flow without acceleration the minimum impellor work $\hbar_{p}$ needed to pump the liquid to the surface is, for a mass flowrate in

$$
\dot{w}_{p}=\dot{m}_{\mathbf{p}} \mathbf{E}_{\mathrm{E}}
$$

(2) If the impellor work exceeds $\dot{W}_{p}$ and the pump suction pressure were to remain unchanged then the flowrate $\dot{m}$ would rise. In general $\dot{m}$ will rise and the suction pressure decline as $W_{p}$ increases until the well reaches the maximum flowrate it can sustain.

(3) If flashing is to be prevented it is necessary to ensure that the fluid pressure exceeds the saturation value for the associated temperature until the location is reached where flashing is required or is acceptable. If flashing is to be suppressed until the exit from the wellbore then the minimum excess pressure the pump must generate is that equivalent to the hydrostatic pressure increment above the flash level. If the liquid density above the flash level has then a mean value of $\bar{p}_{S}$ this minimum excess pressure will be

$$
\Delta \mathrm{P}=\bar{\rho}_{\mathrm{S}} \mathrm{gz} F
$$

which will have to be increased in practice to cover flow losses. 
For the pumped well a step-rise occurs in the pressure as the liquid traverses the pump. The equation (11) can no longer be applied. Two Bernoulli equations are now required, one for the well section below the pump and the other for the well section above the pump. Denoting the suction and delivery pressures by $P_{i}$ and $P_{e}$ and the mean densities of the lower and upper columns by $\bar{\rho}_{\mathrm{L}}$ and $\bar{\rho}_{\mathrm{H}}$, the respective Bernoulli equations now become

$$
\frac{P_{I}-P_{i}}{\bar{P}_{L}}=\frac{2 \bar{f}_{L} z_{E} v^{2}}{D}+g z_{S},
$$

and

$$
\frac{P_{e}-P_{2}}{\bar{P}_{H}}=\frac{2 \bar{f}_{H} z_{F} v^{2}}{D}+g z_{F}
$$

Where $\bar{f}_{L}$ and $\bar{f}_{H}$ are the respective mean values of friction coefficient.

Wells may be pumped by means other than rotodynamic downhole pumps. The principle of one such method is shown in Fig. 4. Nitrogen or other inert gas is forced down the well to displace the liquid trapped above a check valve. When the liquid has been removed the containment volume is vented and the check valve opens to recharge it. A variant of this method is to inject the gas continuously at the wellbottom to provide buoyancy throughout the full column height [See Elliott, 1977].

\subsubsection{CHARACTERISTICS OF THE COMBINED WELL-RESERVOIR SYSTEM}

The subject of drawdown was treated in Section 2.2 .5 and plots were presented showing the pate at which the drawdown pressure difference $\left(\mathrm{P}_{3}-\mathrm{P}_{1}\right.$ for this present Section) for a particular well responded to time under a demand for a modified but thereafter constant mass flowrate. For this well the period of the transient, i.e., the elapsed time before the well-reservoir 
system regained stability was many hours. The recovery time is clearly related to the permeability of the formation, the geofluid viscosity and hence the base temperature, the closed-in pressure and other features of the system. Every well has its own drawdown characteristics.

In the treatment to follow it is assumed that the drawdown is constant, i.e., the well is not operating within the period of the transient.

\subsubsection{Single Phase (Liquid) Self-Flowing System}

In the foregoing sections analysis has been confined to the vertical pipe and no cognizance has been taken of the aquifer from which it draws its supply. It is clear, however, that aquifer and pipe are not independent. Thus if the flow within the pipe increases the pressure at the pipe inlet will fall and the extent of the pressure reduction will depend upon the freedom of flow of the geofluid through the formation, i.e., upon the height and perneability of the reservoir. Consider Fig. 5 which shows a cylindrical reservoir with a radius $R$ and a depth L. Applying Darcy's Law (Section 2.2.4.1) to an elemental sleeve of thickness $d r$ across which the fluid pressure increment is dP, the mass flow is

$$
\dot{m}=\frac{-K 2 \pi R L \rho_{3}}{\mu} \frac{d P}{d x}
$$

or

$$
-\frac{\mathrm{dP}}{\dot{m}}=\frac{\mu}{2 \pi K L \rho_{3}} \frac{d x}{x}
$$

For the conditions shown this integrates to give

$$
\dot{\mathrm{m}}=\frac{2 \pi K L \rho_{3}}{\mu} \frac{\left(P_{3}-P_{1}\right)}{\ln \frac{R}{r}}
$$

From a practical standpoint equation $(27)$ is difficult to use. The radius $R$ of the reservoir is indeterminate and indeed the reservoir will probably not be cylindrical. The quantities $K$ and $\mu$ may not be accurately known. 
However the increase in $\mathrm{P}_{3}-\mathrm{P}_{1}$ consequent upon an increase in the flowrate $\mathrm{m}$ is readily found from wellhead observations and equation (27) can be transposed thus:

$$
\frac{P_{3}-P_{1}}{\dot{m}}=\frac{\mu \ln \frac{R}{r}}{2 \pi K L P_{3}}
$$

The quantity $\left(\mathrm{P}_{3}-\mathrm{P}_{2}\right) / \dot{m}$ is the reduction in wellbottom pressure below reservoir pressure per unit flowrate and is known as the drawdown pressure coefficient. The subject of drawdown transient was treated in Section 2.2.5 and mentioned again briefly in Section 2.6.2. The following analysis assumes that the drawdown coefficient $\left(P_{3}-P_{1}\right) / m$ has attained its stable value and is no longer time-dependent.

We may now consider the self-flowing well-reservoir system Fig. 5a and we will assume for the present that no phase change takes place. Applying equation (11) for the well pipe we have

$$
P_{2}=P_{I}-\frac{2 \bar{p}_{W} f_{W} V^{2} z_{W}}{D}-\bar{\rho}_{W} g z_{W}
$$

Fort the reservoir, the Darcy equation (28) gives, for the steady flow case,

$$
\dot{m}=\frac{2 \pi K L_{1}}{\mu} \frac{\left(P_{3}-P_{2}\right)}{\ln \frac{R}{r}}
$$

which may be transposed to give

$$
P_{1}=P_{3}-\frac{\mu m \ell n(R / r)}{2 \pi K L_{3}}
$$

Combining equations (29) and (30) and observing from mass continuity that $V=4 m / \pi D^{2} \rho_{W}$

$$
P_{2}=P_{3}-\dot{m}\left(\frac{\mu_{-}}{\rho_{3}}\right)\left(\frac{1}{K L}\right) \frac{\ln (R / r)}{2 \pi}-\dot{m}^{2}\left(\frac{1}{\bar{\rho}_{W}}\right)\left(\frac{f_{W}{ }^{2}}{D^{5}}\right) \frac{32}{\pi^{2}}-\bar{\rho}_{W} g z_{W}
$$


Inspection shows that $P_{2}$ is a quadratic in $\dot{m}$. The quantities $\left(\frac{\mu}{\rho_{3}}\right)$, $\left(\frac{l}{\bar{\rho}_{W}}\right)$ are geofluid properties, $\left(\frac{1}{\mathrm{~K} L}\right)$ is an aquifer property and $\left(f_{W} z_{W} / D^{5}\right)$ is a wellpipe property. The terms on the right hand side of the equation are pressure drop increments due, in order, to drawdown, pipe flow friction and hydrostatic head.

\subsubsection{Wellhead Pressure - Flow Rate Characteristic for a Self-Flowing Liquid Well}

\section{(Example)}

Consider a well for which $z_{W}=1500 \mathrm{~m}(4921 \mathrm{ft}), L=300 \mathrm{~m}(984 \mathrm{ft})$, $D=0.254 \mathrm{~m}$ ( 10 in pipe), $R / \mathrm{r}$ is taken to be 500 and the temperature at the well bottom is $220^{\circ} \mathrm{C}\left(428^{\circ} \mathrm{F}\right)$, chosen to avoid flashing within the pipe. We require the flow characteristics of this well for formation permeabilities 5 and 50 md and friction factors $f_{W}=0.004,0.008$ and 0.015 . The closed-in pressure is assumed to be $2.5 \mathrm{MPa}\left(363 \mathrm{lb} / \mathrm{in}^{2}\right)$ and the geofluid is taken to be pure water.

Stated in SI units equation (31) yields

$$
P_{2}=25 \times 10^{5}-\dot{m}\left[\frac{4.8 \times 10^{5}}{K}\right]-5474.4 f_{W} \dot{m}^{2}
$$

Curves calculated from equation (32) are plotted in Fig. 6. The mass flow is observed to be very sensitive to the permeability of the aquifer formation and much less sensitive to the friction factor, especially at the lower permeability. A plot of viscosity $\mu$ with temperature for saturated water is shown on Fig. 7 over the full range of normal exploitable aquifer temperatures and a high base temperature will be seen to provide some compensation for a low permeability. The range of permeability in rocks and soils is very large and ranges from $10^{8}$ md for clean gravel to $10^{-5}$ for certain types of granite. Drawdown pressure difference, $P_{3}-P_{1}$, is also shown on Fig. 6 . 


\subsubsection{Single-Phase (Liquid) Pumped System}

The equation (31) may readily be extended to include the introduction of a downhole pump, as shown in the part diagram Fig. 5b. The main effect of the pump is to introduce a step change in the pressure, $\Delta \mathrm{P}=\mathrm{P}_{\mathrm{e}}-\mathrm{P}_{\mathrm{i}}$, and to increase the velocity through the pipe. Treating, for the moment, the upper and lower sections separately, equations (29) and (30) may now be adjusted to read

$$
P_{2}=P_{3}-\dot{m}\left(\frac{\mu}{\rho_{3}}\right)\left(\frac{I}{K L}\right) \frac{\ln (R / r)}{2 \pi}-\frac{2}{D}\left(\bar{\rho}_{L} \bar{f}_{L} V_{L}^{2} z_{L}+\bar{\rho}_{H} \bar{f}_{H} v_{H}^{2} z_{H}\right)-g\left(\bar{p}_{L} z_{L}+\bar{p}_{H} z_{H}\right)+\Delta P
$$

The change in density across the pump is small and so therefore is the change in velocity. The friction factor is dependent on the Reynolds number and both remain approximately constant. Equation (33) therefore reduces to equation (31) modified by the pump pressure increment term, i.e.,

$$
P_{2}=P_{3}-\dot{m}\left(\frac{\mu}{\rho_{3}}\right)\left(\frac{1}{K I}\right) \frac{\ln (R / r)}{2 \pi}-\dot{m}^{2}\left(\frac{1}{\bar{\rho}_{W}}\right)\left(\frac{f_{W} W}{D^{5}}\right) \frac{32}{\pi^{2}}+\Delta P-\bar{\rho}_{W} g z_{W}
$$

The sum of the constant terms in equation (34) now exceeds those in equation (31) with the effect of lifting the parabolic curve for $\mathrm{P}_{2}$ and enhancing the mass flow $\mathrm{m}$. The pump load-head characteristic can be included by incorporating $\dot{m}=\dot{m}(\Delta \mathrm{P})$ in equation (34). The increased velocity will concurrently increase $f_{W}$ with a consequent fall in $P_{1}$ and an increase in drawdown to match the increased mass flow, As pointed out in Section 2.6.1.6, $\mathrm{P}_{i}$ must remain sufficiently high to avoid cavitation.

\subsubsection{The Two-Phase Self-Flowing Well}

We now consider the case of the self-flowing well in which flashing occurs at some point within the pipe. It is assumed that hot water is delivered from the reservoin into the bottom of the pipe and that the upward flow is everywhere 
in thermal equilibrium so that flashing commences at the level at which the liquid becomes saturated. The sections of pipe above and below the flash level may be considered separately.

Referring to Fig. 8a and denoting the single-phase properties by the subscript SP, we obtain from equation (10) for momentum continuity

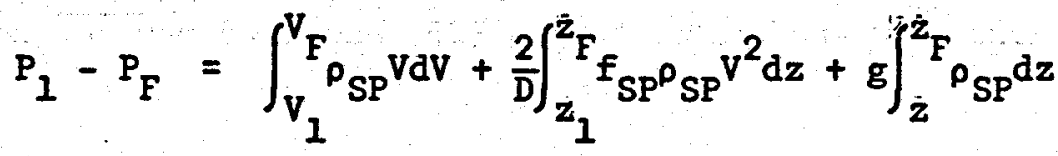

Since $p_{S P}$ is substantially constant over the height $z_{F}^{-z_{I}}=z_{S}$, this gives

$$
P_{I}-P_{F}=\frac{2}{D} f_{S P} \rho_{S P} v_{1}^{2} z_{S}+g \rho_{S P} z_{S}
$$

For the section above the flash level the acceleration term must be included and the corresponding equation is

$$
\begin{aligned}
P_{F}-P_{2} & =\int_{V_{F}}^{V_{2}} \rho_{T P} V d V+\frac{2}{D} \int_{z_{F}}^{z_{2}} F_{T P} \rho_{T P} V^{2} d z+g \int_{z_{F}}^{z_{2}} \rho_{T P} d z \\
& =\bar{\rho}_{T P} \frac{\left(V_{2}^{2}-V_{1}^{2}\right)}{2}+\frac{2}{D} \bar{F}_{T P}{ }_{T P}^{\rho_{T P}} \bar{V}^{2} z_{F}+g \bar{\rho}_{T P} z_{F}
\end{aligned}
$$

where the bar denotes the effective mean value of quantities that vary along $\mathbf{z}_{F}$. Adding equations (35) and (36):

$$
P_{1}-P_{2}=\bar{\rho}_{T P} \frac{\left(v_{2}^{2}-v_{1}^{2}\right)}{2}+\frac{2}{D}\left(f_{S P} \rho_{S P} v_{1}^{2} z_{S}+\bar{f}_{T P} \bar{\rho}_{T P} \bar{v}^{2} z_{F}\right)+g\left(\rho_{S P} z_{S}+\bar{\rho}_{T P} z_{F}\right)
$$

For energy continuity the full expression is given in equation (4a) but to make the present analysis manageable the well will be assumed to be adiabatic and the approximate equation (7) will be employed leading to

$$
x_{2}=\frac{h_{f 3}-h_{f 2}}{h_{f g 2}}
$$


If the well exit, Section 2 , is now considered we may concentrate, for the purpose of modeling, the vapor fraction $x_{2}$ and the liquid fraction ( $\left.1-x_{2}\right)$ into two discrete filaments (Fig. 8b) which have velocities and flow areas given respectively by $v_{g 2}, A_{g 2}$ and $v_{f 2}, A_{f 2}$. The dryness fraction is by definition*

$$
x_{2}=A_{g 2} v_{g 2} P_{g 2} /\left(A_{g 2} v_{g 2} \rho_{g 2}+A_{f 2} v_{f 2} \rho_{f 2}\right)
$$

where $\rho_{g 2}$ and $\rho_{f 2}$ are respectively the saturation values of density for vapor and liquid at the exit pressure $\mathrm{P}_{2}$.

The flow area is

$$
A=\pi D^{2} / 4
$$

and the area occupied only by the liquid filament is

$$
A_{f 2}=A-A_{g 2}
$$

The vapor velocity $v_{g_{2}}$ will nomally exceed the liquid velocity $v_{f 2}$ and the ratio $k_{2}$ is defined as the slip ratio

$$
k_{2}=v_{g 2} / v_{f 2}
$$

Equation (39) may be written in the form

$$
x_{2}=1 /\left(1+\left[A-A_{g 2}\right]_{f 2} / A_{g 2} k_{2} \rho_{g 2}\right)
$$

Mass continuity yields

$$
\dot{m}=\frac{\pi}{4} D^{2} \rho_{S P} V_{1}=A_{g 2} V_{g 2} \rho_{g 2}+\left(A-A_{g 2}\right) V_{g 2} \rho_{f 2} / k_{2}
$$

Inspecting equation (37) it is necessary to considen more closely the quantities $v_{2}, \bar{\rho}_{T P}, \bar{f}_{T P}$ and $\bar{v}$ all of which refer to the two-phase regime. Thus $v_{2}$ is a notional exit velocity for a homogeneous flow $\left(k_{2}=1\right)$ which would This is the mass flow dryness fraction. See Glossary. 
transport the same total exit kinetic energy that is conveyed by the phases, hence

$$
v_{2}^{2} / 2 g=x_{2} v_{g 2}^{2} / 2 g+\left(1-x_{2}\right) v_{f 2}^{2} / 2 g
$$

which from equation (42) gives

$$
v_{2}=v_{g 2}\left(x_{2}+\left[1-x_{2}\right] / k_{2}^{2}\right)^{1 / 2}
$$

The remaining quantities present grave difficulties which will be explored later (Section 2.6.3) in more detail. For the present purpose we may acceptably define the mean two-phase density assuming that $x_{2}$ increases linearly with $z$ over the length $z_{F}$, thus:

$$
\bar{\rho}_{\mathrm{TP}}=\frac{1}{2}\left(\rho_{\mathrm{SP}}+x_{2} \rho_{\mathrm{g} 2}+\left[1-x_{2}\right] \rho_{f 2}\right)
$$

The effective friction factor $\bar{f}_{T P}$ will exceed $f_{S P}$ as a consequence of the enhanced velocity in the section $z_{F}$ and its value will depend upon the variation of $\mathrm{x}$ between stations $\mathrm{F}$ and 2 . It is also dependent upon the prevailing pattern of association between the phases and nannot be stated in terms of the quantities already defined. For the same reason the effective velocity $\bar{v}$ for defining the two-phase friction loss is obscure.

Combining equations (35) through (46) and including the drawdown term the momentum equation analogous to equation (31) becomes

$$
\begin{aligned}
& P_{2}=P_{3}-\left\{\frac{\dot{m} \mu \ln (R / x)}{2 \pi L L_{w 3}}\right\}-\left\{\frac{\bar{p}_{T P}}{2}\left(x_{2}+\left[1-x_{2}\right] / k_{2}^{2}\right) c_{1}^{2 \cdot \dot{m}^{2}}-c_{2}^{2 \cdot m^{2}}\right\}
\end{aligned}
$$

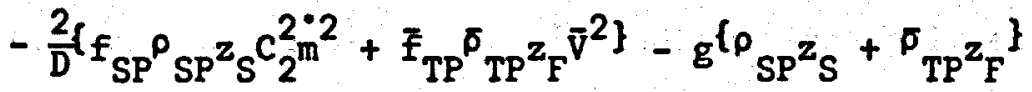

in which

$$
\begin{array}{ll}
v_{g 2}=c_{1} \text { where } & c_{1}=\left(\rho_{f 2}+k_{2} \rho_{g 2}\left[\frac{1}{x_{2}}-1\right]\right) x_{2} / A \rho_{f 2} \rho_{g 2}, \\
c_{2}=4 / \pi D^{2} \rho_{S P}, & \bar{p}_{T P}=\rho_{S P}+\frac{1}{2}\left(x_{2} \rho_{g 2}+\left[1-x_{2}\right] \rho_{f 2}\right)
\end{array}
$$


For a given well, depth $z_{W}=z_{F}+z_{S}$, diameter $=D=2 r$, reservoir pressure $=P_{3}$ and drawdown $=P_{3}-P_{1}$. If the bottomhole temperature is known $h_{f 3}$ is defined. If, also, an arbitrary value of $P_{2}$ is assumed, then $P_{f 2}$ and $P_{g 2}$ are defined, $x_{2}$ can be found from equation (38) and $\bar{p}_{T P}$ from equation (46). For the given well, equation (47) now reduces to the form

$$
P_{2}=A-B m-\phi\left(k_{2}, f_{T P}, f_{S P}\right) \dot{m}^{2}
$$

where $A$ and $B$ are constants and $\phi$ denotes $a$ function of the remaining variables $k_{2}, \bar{f}_{\mathrm{TP}}, \mathrm{f}_{\mathrm{SP}}$. If suitable values can be assigned to these quantities, equation (48) becomes, as for the single-phase well, a quadratic equation in $\dot{m}$. This can be solved and will be found to give a single valid value for the flowrate uf. The equation may also be used to explore the effects of changes in the magnitudes of $\bar{f}_{T P}, f_{S P}$ and $k_{2}$ on the flowrate. Following solution for $m$, resubstitution yields the corresponding values of $\mathrm{V}_{\mathrm{g} 2}, \mathrm{~V}_{\mathrm{f2}}, \mathrm{V}_{2}, \mathrm{~A}_{\mathrm{g} 2}$ and $\mathrm{A}_{\mathrm{f2}}$.

It is not necessary to base the analysis exclusively on the exit section 2 in the manner described above. The equivalent filament method may be employed for any arbitrary flow section within the two-phase region. This permits the . use of a finite interval method for the two-phase sector of the flow and a step-by-step adjustment of $k_{2}, \bar{f}_{\mathrm{TP}}$ and $\mathrm{f}_{\mathrm{SP}}$.

It will be observed that it is not necessary to assume any particular two-phase flow pattern in the above analysis because the arguments arising out of equation (39) are not applicable only to grossly separated flow. If, of course, the flow patterns are known and empirical data available for $\bar{f}_{\text {TP }}$ then the predictive value of the theory is enhanced.

Further discussion of friction factors in two-phase flow will be found in the Appendix. p. 43 . 


\subsubsection{Wellhead Characteristics for a Self-Flowing Flashing Well}

\section{(Example)}

The following data is based upon an actual well, but the flow is assumed to be pure water.

Reservoir temperature, $T_{3}=275^{\circ} \mathrm{C}\left(527^{\circ} \mathrm{F}\right)$; Depth $z_{\mathrm{W}}=1520 \mathrm{~m}(4987 \mathrm{ft}$ ); Diameter $D=0.178 \mathrm{~m}$ (7 in); Drawdown factor $22.8 \mathrm{kPa} / \mathrm{kg} \mathrm{s}^{-1}\left(1.5 \mathrm{lb} \mathrm{in}^{-2} / \mathrm{Ib} \mathrm{s} \mathrm{s}^{-1}\right)$; closed-in pressure $3.4 \mathrm{MPa}\left(493 \mathrm{lb} / \mathrm{in}^{2}\right)$.

The calculation procedure was as follows. An arbitrary value of wellhead pressure $\mathrm{P}_{2}$ was chosen enabling $x_{2}$ to be calculated from equation (38) and defining $\rho_{f 2}$ and. $\rho_{g 2^{*}} V_{2}$ is then expressed in terms of $x_{2}, k_{2}$ from equation (42) and $\bar{\rho}_{\text {TP }}$ from equation (46). Employing equations (40) through (45) enables $v_{2}$ to be expressed as a function of $\dot{m}, k_{2}, x_{2}, A_{2}$ and fluid properties, but since the latter three are already defined, $v_{2}$ becomes a function only of variables $\dot{m}$ and $k_{2} \cdot v_{1}$ is immediately related to $\dot{m}$ by mass continuity and $\bar{v}$ is obtained with sufficient accuracy by

$$
\bar{v}=\frac{\dot{m}}{2 A}\left(\frac{1}{p_{T P}}+\frac{1}{\rho_{S P}}\right)
$$

The flash depth $z_{F}$ was determined from equation (17) taking $\rho_{T}=p_{W}^{\prime}=\rho_{S P}$ and it was assumed constant with $P_{2}$. It will be shown in Section 2.6.2.7 that this is not the case; the flash level moves down somewhat as in increases.

It is now possible to construct equation (47) in which $k_{2}, f_{S P}, \bar{f}_{T P}$ and in remain as unknowns. The value of 0.008 was assigned to $f_{\text {SP }}$ and $f_{\text {TP }}$ for the purpose of this example, and used for all values of $\mathrm{P}_{2}$. The variation of $k_{2}$ was explored and within its likely range of values was not found to be very significant. An arbitrary value was therefore chosen as displayed on Fig. 9. A quadratic equation in $\dot{m}$ now results which yields a unique positive value for m. The remaining quantities of interest can be calculated by resubstitution as required. 
The above procedure was repeated through a series of arbitrary values of $P_{2}$ and gave the results shown in Fig. 9 which may now be appraised.

As the wellhead valve is opened the flowrate in rises rapidly with the fall in $\mathrm{P}_{2}$ for high values of $\mathrm{P}_{2}$, but the slope $\mathrm{dm} / \mathrm{dP}_{2}$ declines as the value of $\mathrm{m}$ attains a constant value at about $0.75 \mathrm{MPa}$. At lower values of $P_{2}$ the m curve would pursue the dotted path, but for the intervention of choking. Any further fall in pressure $\mathrm{P}_{2}$ below about $0.75 \mathrm{MPa}$ does not influence the flowrate. Comparison of this curve with that experimentally obtained from the real well shows good agreement both for shape and location.

The value of $v_{g 2}$ ig seen to rise to about $200 \mathrm{~m} / \mathrm{s}(656 \mathrm{ft} / \mathrm{s})$ at which velocity choking supervenes. It must be remembered that the vapor is moving in association with, but overtaking, the liquid and momentum exchange between the fluids occurs actively. If the vapor had been alone, i.e., in single-phase flow, it would have choked at the normal acoustic velocity $v_{a}=f(r R T)$, which is approximately $500 \mathrm{~m} / \mathrm{s}(1640 \mathrm{ft} / \mathrm{s})$ for saturated steam at $0.75 \mathrm{MPa}$ pressure. The liquid velocity at exit, $V_{f 2}$, is much less than $v_{g 2}$, and is governed by the slip which for this model was chosen arbitrarily, but having regard to the limited experimental data available (Ryley, 1964; Elliot, 1978). The velocity $v_{2}$ nises only to about: $100 \mathrm{~m} / \mathrm{s}(328 \mathrm{ft} / \mathrm{s})$ at the choked condition. This is the velocity which with homogeneous flow would discharge the same aggregate exit kinetic energy as does the combined two-phase flow. The subject of choking is considered in section 2.6.2.8.

Fig. 10 shows the distribution of effective area as between the two phases. It will be observed that notwithstanding the very low values of $x_{2}$ the saturated vapor occupies more than half the pipe area over the whole significant range of wellhead pressure $P_{2}$. This occurs because $\rho_{g 2} \ll \rho_{f 2}$ which also reflects the fact that most of the mass flow is contained in the saturated liquid discharge. 


\subsubsection{The Stepped-Diameter Well}

In the example presented in the last Section it was evident that the maximum flow was limited to about $80 \mathrm{~kg} / \mathrm{s}(186 \mathrm{lb} / \mathrm{s})$ by the comparatively low values of the velocities at the pipe exit when choking occurred. Within the defined conditions there is no way in which these velocities can be increased, but the mass flow may be increased by an increase in the pipe diameter. There is no need to increase the diameter over the whole depth. In the example the water velocity through the pipe below the flash level was only $0.053 \mathrm{~m} / \mathrm{s}$ $(0.174 \mathrm{ft} / \mathrm{s})$ and this could be substantially increased without significant extra frictional losses. The pipe diameter could therefore be increased from the vicinity of the flash level where the high specific volume of the vapor aided by the rising value of $x_{2}$ begins to influence adversely the mass flow.

The theory presented in Section 2.6 .2 .4 can readily be modified to take account of an increase in pipe diameter. The step will normally occur below the flash level. Single phase friction losses must now be allocated to both the narrow bore pipe and the large bore pipe below the flash point. There will also be a pressure loss at the enlargement given by the standard expression

$$
\Delta \mathrm{P}=\mathrm{C \rho}_{\mathrm{SP}} \mathrm{v}_{1}^{2} / 2
$$

where $C$ is the standard loss coefficient for the ratio: Original pipe area/

Enlarged pipe area. The continuity equations for the exit must now, of course, be based on the enlarged area.

Curves illustrating the respective performance characteristics of constant diameter and of stepped-diameter wells have been presented by Elliott [1975], and James [1970] also refers to the subject. 


\subsubsection{Variation in Depth to Flash Level in Self-Flowing We11}

The depth to the flash level, equation (17), is based on the pressures arising from static liquid columns exterion to and within the well and does not Include the pressure losses due to flow friction and drawdown. This subject is now reviewed in greater detail. It was shown in Section 2.6.2:1 that for a single-phase self-flowing liquid well the wellhead pressure is given by equation (3I)

$$
P_{2}=P_{3}-\dot{m}\left(\frac{\mu}{\rho_{3}}\right)\left(\frac{1}{K L}\right) \frac{\ell n(R / r)}{2 \pi}-\dot{m}^{2}\left(\frac{1}{\rho_{W}}\right)\left(\frac{f_{W} z_{W}}{D^{5}}\right) \frac{32}{\pi^{2}}-\bar{\rho}_{W} g z_{W}
$$

where the terms on the right-hand side of the equation represent successive pressure drop increments due, in order, to drawdown, to pipe flow friction and to hydrostatic head. Clearly, equation (31) is also valid for any pressure between $P_{1}$ and $P_{2}$ at whatever value of $z$ it may be located. Specifically, if we wish to locate $z_{F}$ we may write

$$
P_{S}=P_{3}-\dot{m}\left(\frac{\mu}{\rho_{3}}\right)\left(\frac{1}{K L}\right) \frac{\ln (R / r)}{2 \pi}-\dot{m}^{2}\left(\frac{1}{\rho_{W}}\right)\left(\frac{f_{W} z_{F}}{D^{5}}\right) \frac{32}{\pi^{2}}-\bar{\rho}_{W} g z_{F}
$$

Setting the saturation pressure $P_{S}$ at the appropridte value for the reservoir temperature and selecting the required value of $\dot{m}$, the flash depth $z_{F}$ may be found for the full range of in values.

Using the example devised for Section 2.6.2.5 the variation of $z_{F}$ with in has been plotted (Fig. 11b).

It is instructive to consider this topic from a graphic standpoint and the same example has been used.

The static pressure distribution in the well/reservoir combination is shown approximately in Fig. 1la. Pressure fall increments; drawdown, well pipe and wellhead are shown horizontally as a function of depth. Consider first 
the closed-in condition. There will be no drawdown, $P_{1}$ will equal $P_{3}$ and point A locates this condition at the wellbottom. The pressure drop up the pipe will be due only to the decline in hydrostatic pressure and will reach the closed-in value of wellhead pressure at B. Suppose now that the wellhead valve is partially opened. Flow now commences, a wellbottom drawdown pressure drop occurs and the wellbottom pressure assumes the position $C$. The pressure loss up the pipe is now a combination of that due to hydrostatic pressure, acceleration and flow friction. The new wellhead pressure $P_{2}$ is now located at $D$. Increased opening of the wellhead valve moves the pressure distribution line further to the left as shown.

The base temperature in the reservoir defines a saturation pressure at which flashing will commence. This is shown as $\mathrm{P}_{S}$ on diagram $a$, and the points of intersection of $P_{S}$ with $A B, C D$, etc., show the depths at which flashing commences for successive increments of wellhead valve opening. It will be seen that as the wellhead pressure $P_{2}$ falls and the mass flowrate $\dot{m}$ increases the flash level moves down the well. The closed-in case is of special interest in this connection. The line $A B$ intersects pressure $P_{S}$ at point $X$. When the well is closed-in there is no flow and can be no flash level. If, however, the wellhead valve is "cracked" open and a small flow commences, the flash point establishes itself forthwith at the level $\mathrm{x}$.

It should be noted that the pressure lines $A B, C D$, etc., have been shown for convenience as linear. This is very nearly accurate for the whole closed-in Iine $A B$. It is also substantially correct for the remaining lines $C D$, etc., below the flash level. Above the flash level the flow is accelerated, the friction increases and the pressure declines more rapidly causing the lines to curve slightly towards the pressure origin. 
It should also be noted that the values of mass flowrate were calculated on the assumption of a constant depth of flashing and are only approximately correct. They would require iterative recalculation to establish their precise values.

Considering the curves in Fig. 1 lb the drawdown $\mathrm{P}_{3}-\mathrm{P}_{1}$ is seen to be linear as required by the Darcy equation (27) and the depth $z_{F}$ to the flash level is also nearly linear with $\dot{m}$ at the higher values of $\dot{m}$.

It should be borne in mind that the curves presented in Fig. 11 are appropriate only to the example chosen and serve to illustrate principles. Variations in reservoir permeability, base temperature, well depth, well bore, salinity, etc., would yield different characteristics but preserve the general pattern.

\subsubsection{Chóked Flow}

In Section 2.6.2.5 it was shown in the numerical example that the mass flowrate $\dot{m}$ rose with a decline in wellhead pressure $P_{2}$ until a maximum flowrate was reached after which further reduction in $P_{2}$ had no influence on the discharge. This condition, referred to as "choking" is usually encountered though it may be absent in wells with very small values of closed-in pressure. Choking in single-phase gas or vapor flow occurs at a nozzle throat or a pipe exit when the velocity at that section becomes equal to the local sonic velocity thus preventing the upstream propagation of the pressure pulse arising from a further reduction of downstream pressure. The subject is well understood and for an ideal gas the sonic velocity is given by

$$
v_{a}=f(r R T)
$$

where $T$ is the local value of absolute temperature. For any flow having a velocity $V$ at this temperature the Mach number is defined as 


$$
\begin{gathered}
-27- \\
M=V / V_{a}
\end{gathered}
$$

If we now consider the two-phase flow we might have a condition at a pipe exit in which the flow is annular (See Section 2.6.3.1). In such an event the central vapor core is unimpeded and its velocity would rise to the sonic velocity, appropriate to the conditions. The surrounding annular sleeve of liquid would flow more slowly. Complete phase separation across a cylindrical interface is not possible, but sonic models so based have been employed and are known as vapor-choking models [Ryley, 1965].

If, as is usually the case, no such gross separation occurs between the phases the conditions for choking are complex and much ingenuity has been expended in attempting to devise acceptable models. No finality has been reached and the following brief summary of the history leading to the contemporary state of the art must suffice.

Early attempts to understand two-phase flow choking were not related to geothermal steam wells and experiments were conducted with small diameter nozzles and pipes generally in the context of process engineering or nuclear. reactor cooling channels. Two approaches to the study of modeling two-phase flow choking were distinguished by Hewitt and Hall-Taylor [1970]; (1) models which employed similar ideas to those used in single-phase flow and (2) models in which detailed analyses were made within the region leading to the point where the flow becomes critical. Most models fall into category (1) and are discussed below.

For unit mass of a flowing fluid with negligible friction losses in which no potential energy or work terms are involved the energy balance on an element at the critical condition is

$$
-v d P=d\left(\frac{v_{c}^{2}}{2}\right)
$$




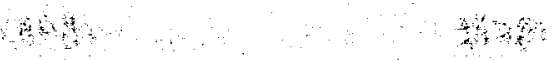

where $V_{c}$ is the critical velocity. Denoting the critical mass flux by $G_{c}$ where

$$
G_{c}=\frac{\dot{m}}{A}=\frac{V_{c}}{V}
$$

equation (54) may be rewritten as

$$
G_{c}^{2}=-\left(\frac{\partial P}{\partial v}\right)_{S}
$$

where the derivative is taken at constant entropy consistent with the assumption of themodynamic reversibility. The same result can be derived from considerations of frictionless momentum transfer.

Different models arise from equation (56) according to the Interpretation of the mean specific volume $v$. This will take account of the proportions of each phase present and may be based on (a) a homogeneous mixture, (b) a flow area, (c) a momentum flux or (d) an energy flux. Investigators employing this general approach include Ryley [1952], Isbin, et al., [1957], Fauske [1961], Cruver and Moulton [1967].

An attempt was made by Bodvarsson and Ryley [1966] to relate the findings of three of the above-named to critical discharge in geothermal wells. They claculated the flow for a given Icelandic well using the methods of Isbin et al., [1957], Fauske [1962] and Cruver [1963]. Cruver's theory, modified by him to take account of supersaturated flow in the exit, gave the best agreement with the results obtained from flow separation at the wellhead.

So far as the writer knows no further attempts have been made to analyse geothermal well critical flow although the subject of two-phase critical flow In general has been vigorously pursued (e.g., DeJong and Firey, 1968; Katto, 1968 and Henry and Fauske, 1971). 


\subsubsection{Estimation of the Mass Flowrate from Wells}

For the satisfactory exploitation of geothermal wells it is necessary to Know with some precision the mass of water and steam discharged. The total mass discharged from a fully open well is large, possibly exceeding $100 \mathrm{~kg} / \mathrm{s}$ $(220 \mathrm{lb} / \mathrm{s})$ and it is generally impracticable to condense it for weighing or volume measurement. The following methods have been employed:

(I) Separation and weighing of the phases. This method was employed in Iceland. Crude separation was effected in a U-bend followed by further separation within a cyclone. The separated vapor was metered using two orifice plates $0.265 \mathrm{~m}(0.87 \mathrm{ft})$ diameter each mounted in a pipe $0.406 \mathrm{~m}$ ( $1.33 \mathrm{ft}$ ) bore. The separated liquid fractions were flashed. The resulting vapor was metered using a $0.145 \mathrm{~m}(0.476 \mathrm{ft})$ orifice and the surviving water was

passed over measuring weirs. A diagram of the equipment, which was portable, is shown by Bodvarsson and Ryley (1966). The equipment was of necessity very bulky and heavy. Mathias [1975] used somewhat similar equipment. Although simple in principle the method can lead to errors as, for example, when steam escapes in small quantities into a separated hot water pipe conveying the water to a measuring orifice [James, 1975].

(2) Sampling across the flow. This method was employed by Banwell [1957] who employed a sampling tube which could be moved diametrally across the flow of a vertical discharge. The mixture collected was condensed in a small calorimeter. By assuming the flow patterns were axisymmetric the integrated flowrate could be found.

(3) Absorption of Beta rays. This method was employed by Belin and Knox [1955] and Belin and Bainbridge [1957]. They measured the density of the mixture by the absorption of beta rays along a vertical throat diameter of a nozzle 
discharging steam and water horizontally. They found that a relation existed between the density and the dryness fraction. The mass discharge could then be calculated from an empirical relation containing the variables; upstream pressure and density.

(4) Sharp-Edged Orifices. Sharp-edged orifices may be used to measure twophase flow throughout the entire dryness fraction range. This subject is very well documented and readers may refer to the long series of researches conducted at the National Engineering Laboratory, Scotland [e.g., Chisholm and Watson, 1966], or to the reference list following Smith and Leang [1975].

(5) All the above methods when used with care are capable of fair accuracy but as in the cases of numbers (1) and (3) especially they may be inconvenient to use on the geothermal well site. A simple empirical method due to James [1962] is widely used because of its great convenience. James showed that by means of a lip pressure tapping at the end of a pipe discharging geothermal fluid critically to the atmosphere a fairly accurate estimate can be made if the stagnation enthalpy of the fluid is known. He used pipe sizes of $76.2 \mathrm{~mm}(3 \mathrm{in}), 152.4 \mathrm{~mm}$ ( $6 \mathrm{in})$ and $203.2 \mathrm{~mm}$ ( 8 in) diameter, a critical pressure range of 0.097 to $0.44 \mathrm{MPa}\left(14\right.$ to $64 \mathrm{lb} / \mathrm{in}^{2}$ abs.) and a stagnation enthalpy range of 535 to $2791 \mathrm{~kJ} / \mathrm{kg}(230$ to $1200 \mathrm{Btu} / \mathrm{lb})$. He claimed that the following empirical equation covers the data with an accuracy of $\pm 3 q$ :

$$
\frac{\mathrm{Gh}^{1.102}}{\mathrm{P}^{0.96}}=11400
$$

where the quantities are in traditional units, i.e., $G$, the mass velocity is in $1 \mathrm{~b} / \mathrm{s} \cdot \mathrm{ft}^{2} ; \mathrm{h}$, the stagnation enthalpy is in Btu/lb and $\mathrm{P}$ the critical discharge pressure is in $1 \mathrm{~b} / \mathrm{in}^{2}$ abs. The corresponding expression in sI units is 


$$
\frac{G^{1.102}}{P^{0.96}}=16.757 \times 10^{6}
$$

where $\mathrm{h}$ is in $\mathrm{kJ} / \mathrm{kg}, P$ in $M P a$ and $G$ in $\mathrm{kg} / \mathrm{m}^{2} \cdot \mathrm{s}$.

\subsubsection{PATTERNS OF TWO-PHASE ASSOCIATION IN VERTICAL TWO-PHASE FLOW}

When hot water rises up a well pipe its pressure falls as the overlying fluid mass decreases. There may be a concurrent fall in temperature or, in rare cases, an increase. Usually, the temperature falls but heat is not normally transported away from the flow sufficiently fast for a rapid temperature decline to take place. In the geothermal well it frequently happens that during the long upward path the pressure of the hot geofluid declines to the saturation value and vapor begins to form.

No direct observations of the subsequent behavior is possible in the geothermal well, but the subject has been studied extensively in other contexts over a period of several years. Frequently a two-component, two-phase mixture (e.g. air-water) has been employed because this permits the use of transparent pipes and channels and makes direct visual observation possible, but at the expense of excluding change of phase. Many experiments exist in which a singlecomponent two-phase mixture, such as steam-water, has been used, but the elevated temperatures may raise problems with transparent containment.

The geometry of association of the phases is complex and varies with the height and many other experimental conditions and many patterns of association ("flow patterns") have been postulated.* General agreement has now been reached on the identities of the significant, frequently-recurring patterns for co-current.flow.

*Sets of flow patterns have also been postulated for horizontal two-phase flow, some patterns differing from those observed in vertical flow and this subject will concern us when considering surface distribution of geofluids. For geothermal well studies we are not concerned with horizontal flow. 
The type of flow pattern at any location within the flow might appear to be irrelevant. It is, however, of consequence in two connections:

(1) If the channel is conveying a coolant subject to evaporation it is vital to know at what location adequate heat transfer from the inner walls to the coolant fails and damage to the channel ("burnout") takes place. This issue does not arise with geothermal wells.

(2) The pressure drop is functionally related to type of flow pattern because the pattern is determined by the void fraction, slip ratio, pressure, velocity, passage geometry, interfacial surface tension, and possibly other factors which collectively influence the mean friction factor.

\subsubsection{Flow Patterns in Vertical Flow}

There is general agreement that four generic types of flow pattern are found in vertical flow and although these cannot be directly observed in the geothemal well it is likely that they occur. They are shown in Fig. 12 and they occur in sequence downstream from the flash level in the following order:

\section{(a) Bubble Flow}

The onset of flashing promotes the formation of vapor bubbles at selected nucleation sites within the liquid and at the liquid boundary. These bubbles have substantially the same size at nucleation, but grow at different rates as a consequence of coalescence and/or continuing vaporization arising from continuing pressure reduction. The vapor is the dispersed phase and the liquid is the continuous phase.

\section{(b) Slug Flow}

Further growth and coalescence of bubbles promotes a succession of large bubbles which have nearly the same cross-section as the pipe. They are bulletshaped and advance at approximately regular intervals separated by lengths occupied mainly by liquid which may or may not contain a dispersion of smaller vapor bubbles. 


\section{(c) Churn Flow}

As the flow proceeds the further generation of vapor occurs and mass continuity necessitates an increasing average fluid velocity as the mean density falls. The slug structure becomes unstable and collapses with consequential "chuming" or oscillatory motion. The size, disposition and movements of the dispersed yapor elements are much less regular than with bubble or slug flow. (d) Annular Flow

With additional generation of vapor it is to be expected that the growing dispersed vapor elements of the three previous cases will eventually coalesce to form a continuous vapor passage within the flow. In annular flow there is a thin liquid film on the channel walls presenting a more or less continuous interface to the vapor core. The liquid film may or may not contain residual vapor bubbles and there may or may not be dispersed liquid within the vapor core. The interface will be geometrically unstable, subject to oscillations and liquid and/or vapor may be transported across it is either direction.

The locations of flow regimes within the wellbore cannot be determined readily using instruments and very few experimental data are available. The flashpoint location is revealed after some months operation in a well with an adequate reservoir on constant load because of the occurrence of deposited precipitate ("calciting"). The restriction so formed may be bored out and the depth thereof is then known. Direct observation of the steam plume from a well discharging into the atmosphere frequently suggests a sheath of liquid leaving the inside wall of the pipe lip [Ryley, 1962; Belin and Bainbridge, 1957; Soda, et al., 1975]. Traversing the efflux with a sampler supports this view [Banwell, 1957]. 


\subsubsection{Transition of Flow Pattern}

The factors which determine transition from one flow pattern to the sequential one have' attracted much study for about two decades. It is now possible to give satisfactory qualitative explanations of the operation of these factors but difficult to devise acceptable models for predictive analysis. In any case, models can only be based on and tested by physical observations and all such data derives from pipes and channels providing a flow area at least an order of magnitude smaller than that provided by the bore of a geothermal well. The relevance of existing knowledge to the case of the well is therefore in grave doubt. The current position has been authoritatively summarized by Dukler [1977].

Observations on flow patterns have led to the construction of flow pattern diagrams which purport to display the boundaries dividing the different patterns plotted against rectangular axes based on those property groups believed to be significant variables. Many such diagrams exist and many have been surveyed by Vohr [1960] and Scott [1963]. Since 1963 a number of new diagrams have become available. No finality, however, has been reached. It is easy to show the locus of conditions representing flow in a tested well on many of these diagrams [Ryley, 1966; Bodvarsson and Ryley, 1966] and the curves obtained may appear plausible inasmuch that the flow traverses the expected regions and may become annular at exit. Such exercises must, however, be viewed with great caution as the flow pattern boundaries may have been based on experimental work performed in apparatus and with conditions very different from the geothermal well.

\subsubsection{THERMODYNAMIC AVAILABILITY IN GEOTHERMAL SYSTEMS}

The subject of themodynamic availability will be treated formally later (Chapter 3, Section 4) and the reader should consult this Section for an 
introduction to this concept. The specific thermodymamic availability is defined as

$$
\mathbf{b}=\mathbf{h}-\mathbf{T}_{\mathbf{0}} \mathbf{s}
$$

where $h, T$ and $s$ have their usual meanings and the subscript o refers to the "dead state." This concept will be applied first to the well pipe alone and then to the system comprising the well pipe, the downhole pump (if any) and the power plant.

\subsubsection{Availability analysis of the Well Pipe}

Consider a well pipe, Fig. $13_{2}$ and let subscripts 1 and 2 respectively denote the entry and exit sections. The following refers to unit mass of geofluid

Availability at wellbottom, $b_{1}=h_{1}-T_{0} s_{1}$

Availability at wellhead, $\quad b_{2}=h_{2}-T_{0} s_{2}$

Loss in availability $\Delta b$ during the ascent of the geofluid

$$
\Delta b=b_{1}-b_{2}=h_{1}-h_{2}-T_{0}\left(s_{1}-s_{2}\right)
$$

For a well with no pump the steady flow energy equation gives

$$
\dot{Q}=\left(h_{2}+\frac{v_{2}^{2}}{2}+g z_{2}\right)-\left(h_{1}+\frac{v_{1}^{2}}{2}+g z_{1}\right),
$$

or

$$
h_{1}-h_{2}=\frac{1}{2}\left(v_{2}^{2}-v_{1}^{2}\right)+g\left(z_{2}-z_{1}\right)-Q
$$

By equations (63) in (62),

$$
\Delta b=\frac{1}{2}\left(v_{2}^{2}-v_{1}^{2}\right)+g\left(z_{2}-z_{1}\right)-\dot{Q}-T_{0}\left(s_{1}-s_{2}\right)
$$

If there is a loss of heat from the well $\dot{Q}$ is-ve and $\Delta b$ increases; if heat is gained $\dot{Q}$ is tre and $\Delta b$ diminishes. For the adiabatic well $\dot{Q}=0$ and 


$$
\Delta b=\frac{1}{2}\left(v_{2}^{2}-v_{1}^{2}\right)+g\left(z_{2}^{\left.-z_{1}\right)-T_{0}\left(s_{1}-s_{2}\right)}\right.
$$

It is seen that the loss of availability of the fluid is increased if the geofluid gains kinetic energy in transit. Since flashing will nomally occur within the vell the mean density of the fluid will fall and $v_{2}$ will exceed $v_{1}$. If, however, subcooled water is delivered at the exit then $v_{2}=v_{1}$ and

$$
\Delta b=g\left(z_{2}-z_{1}\right)-T_{0}\left(s_{1}-s_{2}\right)
$$

If the flow is wholly free from friction losses, $i . e .$, is isentropic, then $s_{1}=s_{2}$, whence

$$
\Delta b=g\left(z_{2}-z_{1}\right)
$$

This loss of availability is unavoidable in the self-flowing well because the geofluid cannot be exploited unless it is raised to the surface and its potential energy gain can only be offset by an equivalent availability loss.

The effect of friction in the flow is to diminish $v_{2}$ and increase $s_{2}$ in equation (65). Friction is related to the other flow parameters through equation (10) and there is no simple way in which the coefficient of friction $f$ can be introduced into equation (65). It is evident, however, that if no wall or fluid friction occurred, i.e., the expanding flow was isentropic, then the loss of availability would equal the gain in exit fluid kinetic energy. Since the latter might be in part recoverable in the plant the loss may be partly retrievable. On the other hand frictional reheating of any kind will generate entropy and promote an increase in $s_{2}$. The availability loss component $\mathrm{T}_{0}\left(s_{1}-s_{2}\right)$ represents energy lost beyond recovery.

When assessing the possible output for a power plant it is more realistic to relate it to the availability of the geofluid than its enthalpy inasmuch 
that only part of the enthalpy can be converted to mechanical work. Because the ultimate energy source is the downhole fluid it can be argued that the downhole availability should be taken as the datum value. This is tantamount to regarding the well pipe as part of the energy conversion plant. Conversely it can be plausibly argued that the availability loss due to potential energy gain must necessarily be incurred and that well construction gives little scope for the reduction of flow losses hence it is realistic to take the wellhead availability as the datum. Unfortunately the downhole and wellhead availabilities cannot readily be related and the one predicted from the other because, as was shown in Section 2.6.2.4, the two-phase flow is too complex for rigorous analysis.

Availability curves are shown in Fig. 14 for slightly superheated steam and for saturated water both at a pressure of $2 \mathrm{MPa}\left(290 \mathrm{lb} / \mathrm{in}^{2} \mathrm{abs}\right)$ and a steam temperature of $250^{\circ} \mathrm{C}\left(482^{\circ} \mathrm{F}\right)$ at the wellhead. The rejection temperature from the conversion device is plotted as base down to $15^{\circ} \mathrm{C}$, an arbitrary value for the environment.

If one assumes that these conditions are associated with a well of depth $2000 \mathrm{~m}$ (6562 ft) the additional potential energy, were it available, would add only $9.81 \times 2000 / 1000=19.62 \mathrm{~kJ} / \mathrm{kg}(8.4 \mathrm{Btu} / \mathrm{lb})$ to the availability. If for the same reservoir conditions the efflux velocity had been $200 \mathrm{~m} / \mathrm{s}$ $(656 \mathrm{ft} / \mathrm{s}$ ) the wellhead availability would have been diminished by $20 \mathrm{~kJ} / \mathrm{kg}$ (8.6 Btu/lb). Because of their small relative magnitudes potential energy and kinetic energy terms are often disregarded in availability calculations. Some tabulated values of the availability ("exergy") of geothermal water (pure) have been published by Bodvarsson and Eggers [1972]. 


\subsubsection{Availability analysis of the Well Pipe - Power Plant System}

Consider now the geothermal well and associated power plant shown in Fig. 13. In the arguments to follow no restrictions are placed on the nature of the well or of the power plant. A thermodynamic system boundary is drawn as shown around the complete plant. Reference positions are designated $1, e, i, 2$ as indicated and the thermodynamic "dead" state has reference 0 . The thermodynamic availability is given by:

At the well entrance, Section 1 ,

$$
b_{1}=h_{1}-T_{0} s_{1}
$$

At the dead state,

$$
b_{0}=h_{0}-T_{1} s_{0}
$$

The maximum available work from the plant is

$$
w^{0}=b_{1}-b_{0}=\left(h_{1}-h_{0}\right)-T_{0}\left(s_{1}-s_{0}\right)
$$

Suppose the well is pumped by a pump driven by energy which was originally transferred across Section 1 as part of the steady energy flux, then since the reference state is unaltered the maximum available work $w^{\circ}$ from the plant remains the same. This does not mean that the output $W$ from the plant is unaltered; $W$ is, of course, diminished. This is evident by recognizing that the energy required to drive the pump remains within the system and the overall effect of thus driving the pump is to dissipate energy internally and hence. generate entropy. The operation is equivalent thermodynamically to introducing frictional irreversibilities within the system.

Consider now the case where the pump is externally driven and energy is supplied at the rate of $\dot{w}_{p}$ by a source outside the system boundary. The effect of the pump may be analyzed by considering a short section of the well 
flow embracing the pump. The fluid enters this section at level $i$ and leaves at level $e$. If the flow is adiabatic between these levels, the steady flow energy equation reads

$$
+\dot{H}_{p}=\left(h_{e}+\frac{v_{e}^{2}}{2}+g z_{e}\right)-\left(h_{i}+\frac{v_{i}^{2}}{2}+g z_{i}\right)
$$

The availability at the pump entry is

$$
b_{i}=\left(h_{i}-T_{0} s_{i}\right)
$$

and at the pump exit is

$$
b_{e}=\left(h_{e}-T_{0} s_{e}\right)
$$

The change in availability across the pump is therefore

$$
{ }_{p} b_{p}=b_{e}-b_{i}=\left(h_{e}-h_{i}\right)-T_{0}\left(s_{e} e^{-s_{j}}\right)
$$

The enthalpies are related through equation (70) whence

$$
\Delta_{b_{p}}=\dot{w}_{p}-\left(\frac{v_{e}^{2}-v_{i}^{2}}{2}\right)-g\left(z_{e}-z_{i}\right)-T_{0}\left(s_{e}-s_{i}\right)
$$

If the velocity change across the pump is zero and the small potential energy difference $g\left(z_{\left.e^{-z_{i}}\right)}\right.$ is neglected, then

$$
\Delta b_{p}=\dot{W}_{p}-T_{0}\left(s_{e}-s_{i}\right)
$$

If, finally, the pump operation is isentropic, $s_{e}=s_{i}$, then

$$
\Delta_{p}=\dot{\hat{W}}_{\mathbf{p}}
$$

In the ideal case for a perfect external pump the availability is therefore increased by the amount of the pump work. This conclusion is thermodynamically independent of the pump location within the well, and of the nature of the phase or phases pumped. Practical considerations, however, influence the pump location (see Section 2.6.1.6). 


\subsubsection{Utilization Factor}

If the shaft work output from a power plant is $w$, the ratio: work output/ avallability defines the Plant Utilization Factor, i.e.,

$$
\text { Utilization Factor, } n_{u}=\frac{\dot{W}}{W^{0}}
$$

Also

$$
\dot{W}^{0}=\dot{W}-T_{0}
$$

where $\dot{\theta}$ is the aggregate specific entropy production rate within the plant. Any complete plant or subdivision thereof may be defined as a themodymamic system and every thermodynamic system is subject to its own individual availability loss which arises from its individual Imeversibilities. Because of the great number of possible arrangements of components in power plants each assembly yields its own value of $\dot{\theta}$ which can only be found by detailed analysis. This subject will be treated in detail in chapter 4.

\subsubsection{The Dead State}

It is usual when defining the dead state to take as temperature datum that of the ambient ain surrounding the plant. With geothernal plants, however, environmental considerations favor the reinjection of the hot spent fluid. A fairer basis for defining $\eta_{u}$ is to take $T_{0}$ to be the reinjection fluid temperature. At the time of writing (1978) the technology of reinjection is not well developed and it is difficult to predict a meaningful magnitude for $T_{0}$ 


\section{GLOSSARY}

Adiabatic Hell - A well in which there is no heat transfer in either direction between the rising geofluid and the containing pipe.

Drymess Fraction - The mass of saturated vapor contained in unit mass of a mixture of saturated vapor and saturated liquid. The dryness fraction may similarly be defined in terms of the constituent volumes. In either case the proportions may be referred (a) To the mixture in transit across a defined section within the flow, or (b) To the mixture existing instantaneously within a defined themodynamic system. The functional relationships among these dryness fractions, variously defined, are given by Ryley [1964].

"Cracked" Open - A slang term in wide use to denote a valve which has been turned slightly on to permit a small flow through.

Cavitation - The production of small vapor bubbles on the surface of a pump impellor as a consequence of pressure reduction within the liquid being pumped. Collapse of these bubbles may cause erosion of the blade surface.

Check Valve - An automatic non-retumn valve usually employed with liquids.

Choking - A nozzle or flow section is said to be choked when it is passing the maximum mass of fluid possible for the prevailing reservoir conditions.

Equivalent Filament - An imaginary single stream of liquid (or vapor) which will convey the same integrated mass (energy, momentum, etc.) as is conveyed by this same liquid (or vapor) when moving in a complex flow pattern.

Flash Level - The depth below the surface of a well at which phase change from saturated water to saturated vapor first occurs.

Flow Pattern - A pattern of association between the vapor and the liquid phases in two-phase flow which can be identified as one of a number of well-recognized catagories.

Geofluid - A general term for the effluent from a geothermal well; sometimes referwed to as "brine." The term generally refers to liquid which will normally contain salts and/or gases in solution or association.

Homogeneous - A two-phase mixture may be treated as a pseudofluid that obeys the usual equations for single-component flow. Suitable average properties are defined and the integrated velocity difference between the phases is zero.

Lip Pressure Tapping - A static pressure hole situated as near as convenient to the exit of a pipe discharging critically to the atmosphere. Used to measure critical mass flowrate. 
Metastable - A condition of thermodynamic disequilibrium of short duration occurring iminediately before any phase change.

Quality See Dryness Fraction

Rotodynamic Pump - A rotary pump other than a positive displacement pump.

Slip - In two-phase flow the respective integrated velocities of the two phases may differ, the vapor velocity generally exceeding the liquid velocity. This is referred to as slip.

Static Well - A well which is "closed-in" by the closure of the wellhead valve. No flow occurs and the interior fluid adjusts its conditions according to the prevailing temperature and pressure, the height of the water table, etc.

Water Table - In permeable strata, the interface between air and groundwater within the ground.

Wellhead Valve - The master stop-valve used at the exit from a geothemal well. 


\section{APPENDIX}

\section{FRICTION FACTORS IN TWO-PHASE FLOW}

When fluids are conveyed through channels friction losses are always present and are incurred within the fluid and at the fluid boundary. Friction reveals itself as a flow-wise fall in total pressure and engineers have long been concenned to understand and minimize its effect. Friction in singlephase flows is well understood and ample information is available for the accurate assessment of losses in all contexts of interest. Friction in twophase flow has proved very intractable. It has been intensively studied over the last two or three decades but no definitive theory has been formulated. Published material, while very extensive, remains largely empirical.

It is against this background that flow in geothermal wells must be appraised with the added disadvantage that almost all two-phase flow studies whether single- or two-component have been undertaken in small channels and usually in the laboratory.

The traditional approach to friction in homogeneous single-phase flows is via the correlation between friction factor and flow Reynolds number:

$$
\mathbf{f}=\phi(\operatorname{Re})
$$

The same outlook has been adopted for two-phase flows, whence by analogy,

$$
f_{T P}=\phi\left(R e_{T P}\right)=\phi\left(\frac{4 G A}{\mu_{T P}}\right)
$$

This incurs the difficulty of obtaining a satisfactory definition for twophase viscosity and it is usual to devise an expression which recognizes the mass proportions of both saturated liquid and saturated vapor [Isbin, et al., 1957; Cicchitti, et al., 1960 and Dukler, et al., 1962].

The most commonly used method of calculating two-phase pressure drops was 
devised by Martinelli and co-workers [Lockhart and Martinelli, 1949; Martinelli and Nelson, 1948]. The theoretical justification for their approach is obscure and the method may be regarded as empirical. They defined parameters as follows

$$
\begin{aligned}
\phi_{g}^{2} \text { or } f & =\left[\frac{\left(d P_{F} / d z\right)}{\left(d P_{F} / d z\right)_{g} \text { or } f}\right] \\
x^{2} & =\left[\frac{\left(d P_{F} / d z\right)_{f}}{\left(d P_{F} / d z\right)_{g}}\right]
\end{aligned}
$$

where $\left(\mathrm{dP}_{F} / \mathrm{dz}\right)_{\mathrm{g}}$ and $\left(\mathrm{dP}_{\mathrm{F}} / \mathrm{dz}\right)_{F}$ are the pressure gradients for the vapor and liquid phases respectively flowing alone in single-phase flow within the channel. Plots are presented of the parameters $\phi_{g}$ or $\phi_{f}$ against the parameter $X$, different lines being defined depending on whether the flows of the singlephase fluids are by definition laminar or turbulent.

The Lockhart-Martinelli model failed to give good correlations for steam water mixtures at high pressure. This led to the modified model by Martinelli and Nelson [1948] and to several other models, one of the more successful being proposed by Baroczy [1965].

Dukler, et al., [1964] studied frictional pressure drop in two-phase flow by developing correlations between the pressure drop and the other variables contributing thereto using the principles of similarity. They analyzed a very wide range of data. In discussing the best means of assessing the magnitude of friction factors for various flow patterns Dukler [1977] recommends the similarity method for bubbly flow and for annular flows. For slug flow he advocates using the value based on the equivalent single-phase liquid flow. The current [1978] position regarding experimental data from operating geothermal wells is very unsatisfactory. It is imperative to secure for analysis much more data from as wide a variety of wells as possible. Most needed are depthwise pressure and temperature traverses for each well operating at various discharge rates. 


\section{REFERENCES}

To avoid repetition the following two publications are referred to by the abbreviations given

Proceedings of the United Nations Symposium on the Development and Utilization of Geothermal Resources, Pisa, 22 Sept.-1 Oct., 1970 -- Pisa

Proceedings of the Second United Symposium on the Development and Use of Geothermal Resources. San Francisco, Ca. 20-29 May, 1975 -- SF

1. Austin, A.L., [1977] "Status of the development of the total flow system for electric power production from geothermal energy," CATMEC Report No. 4, Appendix C, May 1977, Division of Engineering, Brown University, Providence, RI 02912.

2. Banwell, C.J., [1957] "Flow sampling and discharge measurement in geothermal bores," ASME Trans., 79, pp. 269-278.

3. Banwell, C.J., Cooper, E.R., Thompson, G.E.K., and McCree, K.J., [1957] "Physics of the New Zealand thermal area," N. Z. Dept. Sci. Ind. Res. Bull., 123, 109 pp., 1957.

4. Baroczy, C.J., [1965] "A systematic correlation for two-phase pressure drop," A.I.Ch.E.J. Preprint No. 37. Eighth National Heat Transfer Conference, Los Angeles, Ca.

5. Belin, R.E., and Knox, F.B. [1955] "The estimation of the distribution and quantity of water in two-phase steam-water systems," New Zealand J. of Sci. and Technology, 37, 3 pp. 385-395.

6. Belin, R.E., and Bainbridge, A.E. [1957] "Estimation of dryness fraction and mass dischange of geothermal bores," Proc. Instn. mech. Engrs., 171, 36, pp. 967-982.

7. Bodvarsson, G., and Eggers, D.E., [1972] "The exergy of thermal water," Geothermics, 1, 3, pp. 93-95.

8. Bodvarsson, G., and Ryley, D.J., [1966] "The measurement of the weight discharge from geothemnal steam wells," Jökull, III, 16 ar Reykjavik, 1966, pp. 184-198.

9. Chisholm, D., and Watson, G.C., [1966] "The flow of steam-water mixtures through sharp-edged orifices," National Engineering Laboratory, East Kilbride, Scotland. Report No. 213, Jan. 1966.

10. Cicchitti, A., Lombardi, C., Silvestri, M., Soldaini, G., and Zavattarelli, R., [1960] "Two-phase cooling experiments - pressure drop, heat transfer and burnout measurements," Energia Nucleare, 7, 6, pp. 407-25.

11. Cruver, J.E., and Moulton, R.W., [1967] "Critical flow of liquid-vapor mixtures," A.I.Ch.E.J., 13, pp. 52-60. 
12. Cruver, J.E., [1963] "Metastable critical flow of steam-water mixtures" Thesis, University of Washington, 1963.

13. DeJong, V.J., and Firey, J.C. [1968] "Effect of slip and phase change on sound velocity in steam-water mixtures and the relation to critical flow," Proc. Des. and Eng. IEC, 7, p. 454.

14. Dukler, A.E., Hicks, K., and Cleveland, R. [1962] "Pressure drop and hold-up in two-phase flow: Part A, A comparison of existing correlations; Part B, An approach through similarity analysis," see A.I.Ch.E. Journal, $10,1, \mathrm{pp} .38-51$.

15. Dukler, A.E., [1977] "Modeling void fractions: A new method for predicting flow regimes in geothemal wells," Report No CATMEC/6, Dec. 1977, Division of Engineering, Brown University, Providence, RI 02912.

16. Elliott, D.G. [1975] "Comparison of brine production methods and conversion processes for geothermal electric power generation," EQL Report No. 10, July, 1975, California Institute of Technology, Pasadena, CA 91125.

17. Elliott, D.G. [1977] "Production well flow," CATMEC Report No. 3, Feb. 1977, Division of Engineering, Brown University, Providence, RI 02912.

18. Elliott, D.G., [1978] "Analysis of EMI6-29 Well Flow Data," CATMEC Report No. 10, Mar. 1978, Division of Engineering, Brown University, Frovidence, RI 02912.

19. Fauske, H.D. [1961] "Critical two-phase steam-water flows," Proc. 1961 Heat Transfer and Fluid Mechanics Institute, p. 79. Stanford University Press, Stanford, CA 94305.

20. Fauske, H.K., [1962] "Contribution to the theory of two-phase, onecomponent critical flow," Thesis, University of Chicago, 1962.

21. Fukuda, M., Aosaki, K., and Sekoguchi, K. [1975] "Some considerations on well characteristics at Otaki and Hatchobaru geothermal areas, Japan," SF, 3, pp. 1643-1649.

22. Gould, T.L. [1974] "Vertical two-phase steam-water flow in geothermal wells," J1. Petrol. Technology, 26, pp. 833-842, Aug. 1974.

23. Henry, R.E., and Fauske, H.K. [1971] "The two-phase critical flow of onecomponent mixtures in nozzles, orifices and short tubes," J. Heat Transfer, 93, 2, pp. 179-187.

24. Hewitt, G.F., and Hall-Taylor, N.S. [1970] "Annular two-phase flow," Pergamon Press.

25. Isbin, H.S., Moy, J.E., and daCruz, A.J.R. [1957] "Two-phase steam-water critical flow," A.I.Ch.E. Journal, 3, Pp. 361-365.

26. James, R. [1962] "Steam-water critical flow through pipes," Proc. Instn. Mech. Engrs., 176, 26, pp. 741-748. 
27. James, R. [1970] "Factors controlling borehole performance," Pisa, 2, 2, pp. 1502-1515.

28. James, R. [1975] "Possible serious effect of the presence of steam on hot water flow measurements utilizing an orifice meter," SF, 3, Pp. 1703-1206.

29. Katto, Y., [1968] "Dynamics of compressible saturated two-phase flow (critical flow)" JSME, 11, 48, pp. 1135-1144.

30. Lockhart, R.W., and Martinelli, R.C., [1949] "Proposed correlation of data for isothermal two-phase, two-component flow in a pipe;" Chen. Eng. Prog. 45, p. 39.

31. McNitt, J.R., [1963] "Exploration and development of geothermal power in California," Calif. Div. Mines Geol. Spec. Rept. 75, 45 pp., 1963.

32. McNitt, J.R., [1965] "Review of geothermal resources," Terrestrial Heat Flow, Amer. Geophys. Union (Nat. Acad. Sciences) Publication No. 1288, (W.H.K. Lee, Editor), pp. 240-266.

33. Martinelli, R.C. and Nelson, D.B. [1948] "Prediction of pressure drop during forced circulation boiling of water," ASME Trans. 70, pp. 695-702.

34. Mathais, K.E. [1975] "The Mesa geothermal field - a preliminary evaluation of five geothermal wells," SF, 3, Pp. 1741-1747.

35. Nathenson, M. [1974] "Flashing flow in hot-water geothermal wells," J1. Research U.S. Geol. Survey, 2, 6, pp. 743-751, Nov.-Dec. 1974.

36. Ryley, D.J. [1952] "The flow of wet steam," The Engineer, 193, 332 (I), 363 (II), March 7-14, 1952.

37. Ryley, D.J. [1964a] "Property definition in equilibrium wet steam," Int. J. Mech. Sci., 6, pp. 445-454.

38. Ryley, D.J. [1964b] "Two-phase critical flow in geothermal steam wells," Int. J. Mech. Sci., 6, pp. 273-285.

39. Ryley, D.J. [1965] "Two-phase critical mist flow;" Symposium on Two-Phase Flow, Dept. of Chem. Engrg., Univ. of Exeter, England, Paper G301, June 1965.

40. Ryley; D.J. [1966] Contribution to R. James; "Metering of steam-water two-phase flow by sharp-edged orifices," Proc. Instn. Mech. Engrs., $180, \mathrm{I}, 23$, Pp. 549-572, 1965-6.

41. Scott, D.S. [1963] "Properties of co-current liquid-gas flow," Advances in Chem. Engrg. 4, Academic Press, New York.

42. Smith, R.V. and Leang, J.T. [1975] "Evaluation of correlations for twophase flowmeters, three current - one new," J. Eng. for Power, Oct. 1975, pp. 589-595. 
43. Smith, J.H. [1970] "Geothermal development in New Zealand," Pisa, 2,1, pp. 232-247.

44. Soda, M., Takahashi, Y, , Aikawa, K., Kubota, $K_{,}$and Ejima, Y. [1975] "Experimental study on transient phenomena in steam-water mixtures flowing through a large pipeline for geothermal power stations," SF, 3, pp. 1789-1795.

45. Vakin, E.A., Polak, B.G., Sugrobov, V.M., Erlikh, E.N., Belousov, V.I., and Pilipenko, G.F. [1970] "Recent hydrothermal systems of Kamchatka," Pisa, 2, 2, pp. 1116-1133.

46. Vohr, J.H. [1960] "Flow patterns of two-phase flow - a literature survey," TID-11514 (Quoted in Ref. 24).

47. Yuhara, K. [1970] "Estimation of hydrothermal system by means of wellhead observations," Pisa, 2, 2, Pp. 1458-1462.

48, Yuhara, K, and Tomosada, A. [1965] "Thermodynamical properties of natural steam and hydrothermal structure of Beppu geothermal area," Spec. Contr. Geophys. Inst. Kyoto Univ., 5, 33. 



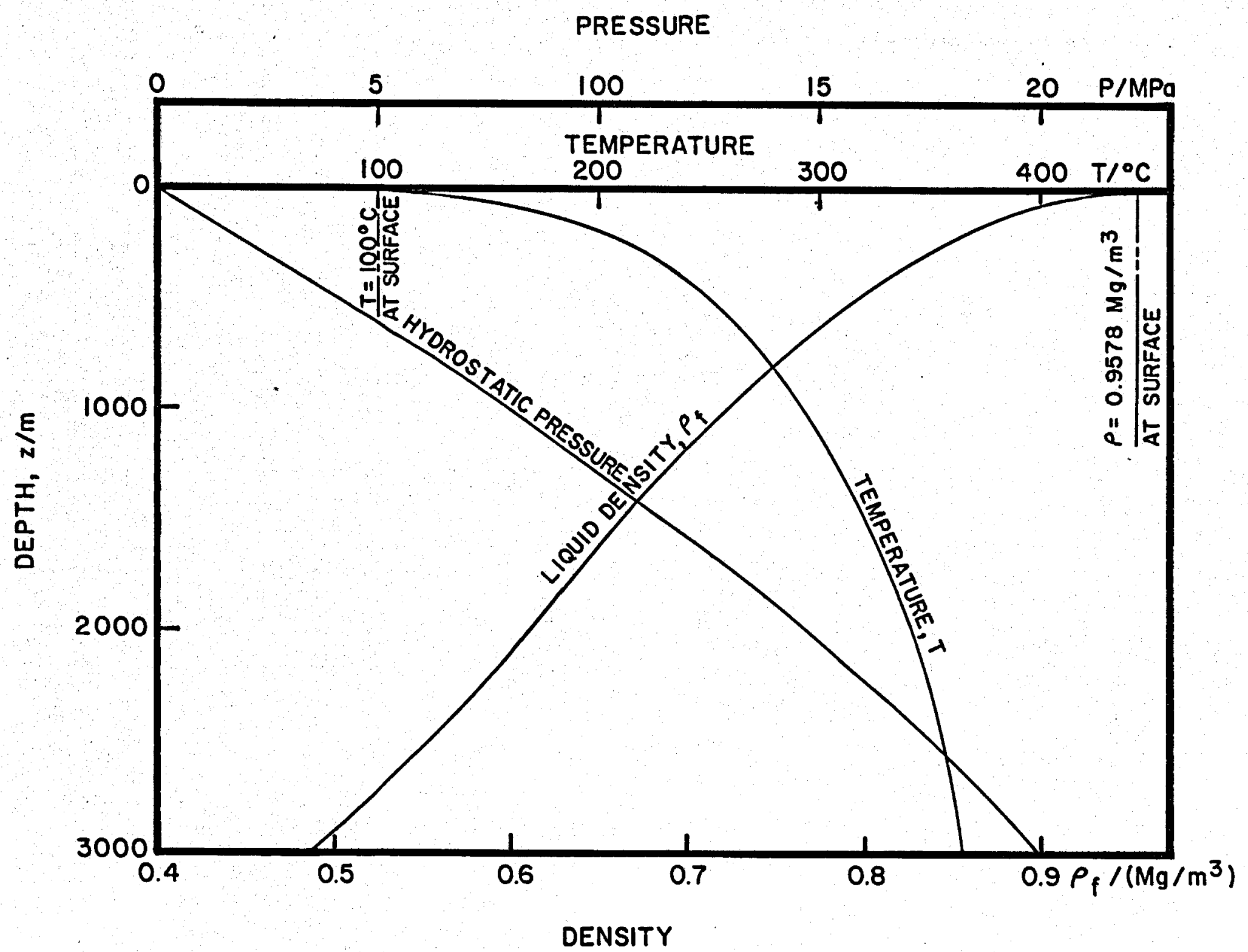

TEMPERATURE, HYDROSTATIC PRESSURE AND LIQUID DENSITY

FOR A PURE WATER COLUMN SATURATED AT ALL LEVELS

FIG. 2 


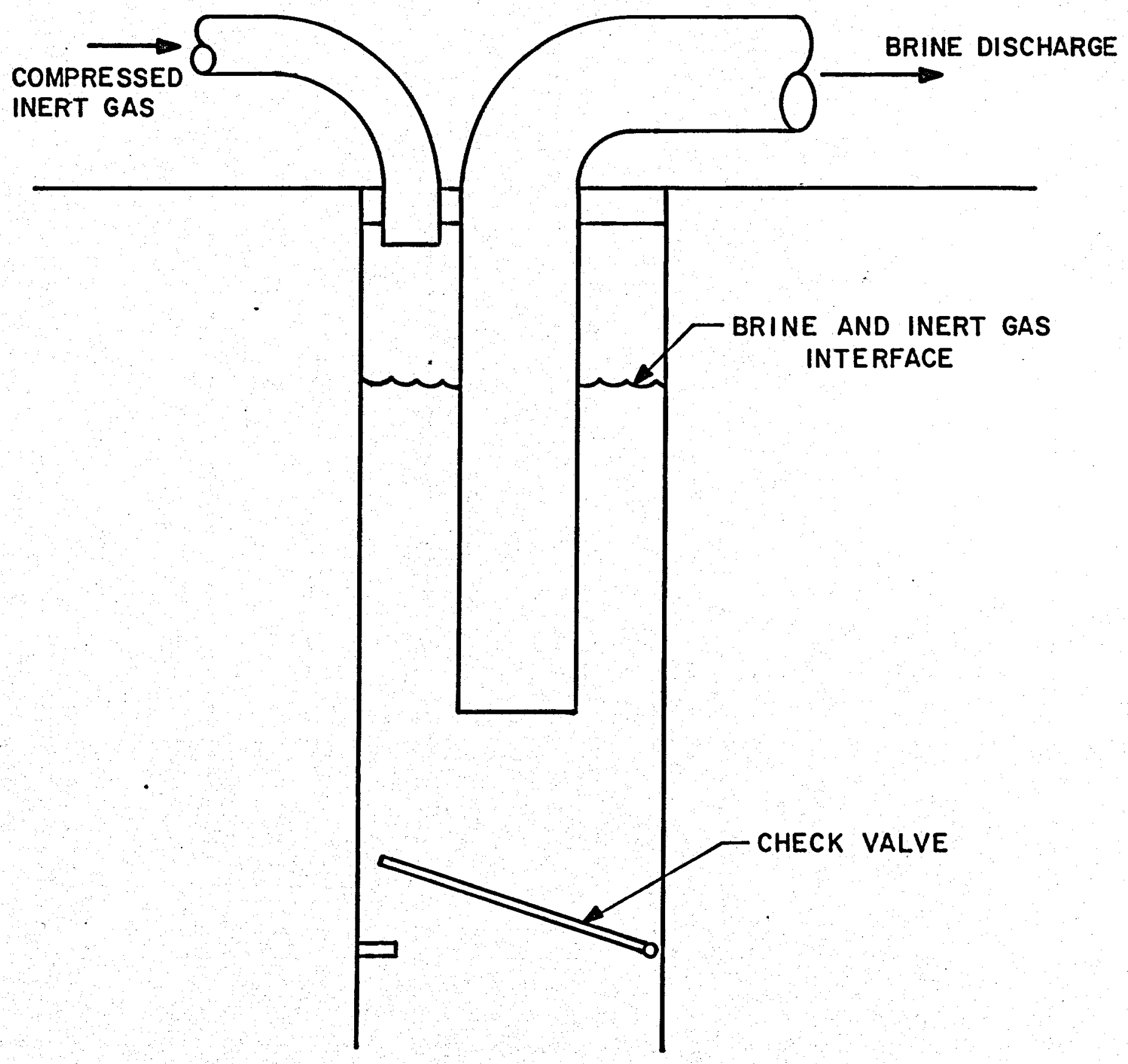

WELL PUMPING BY COMPRESSED GAS

FIG. 4 


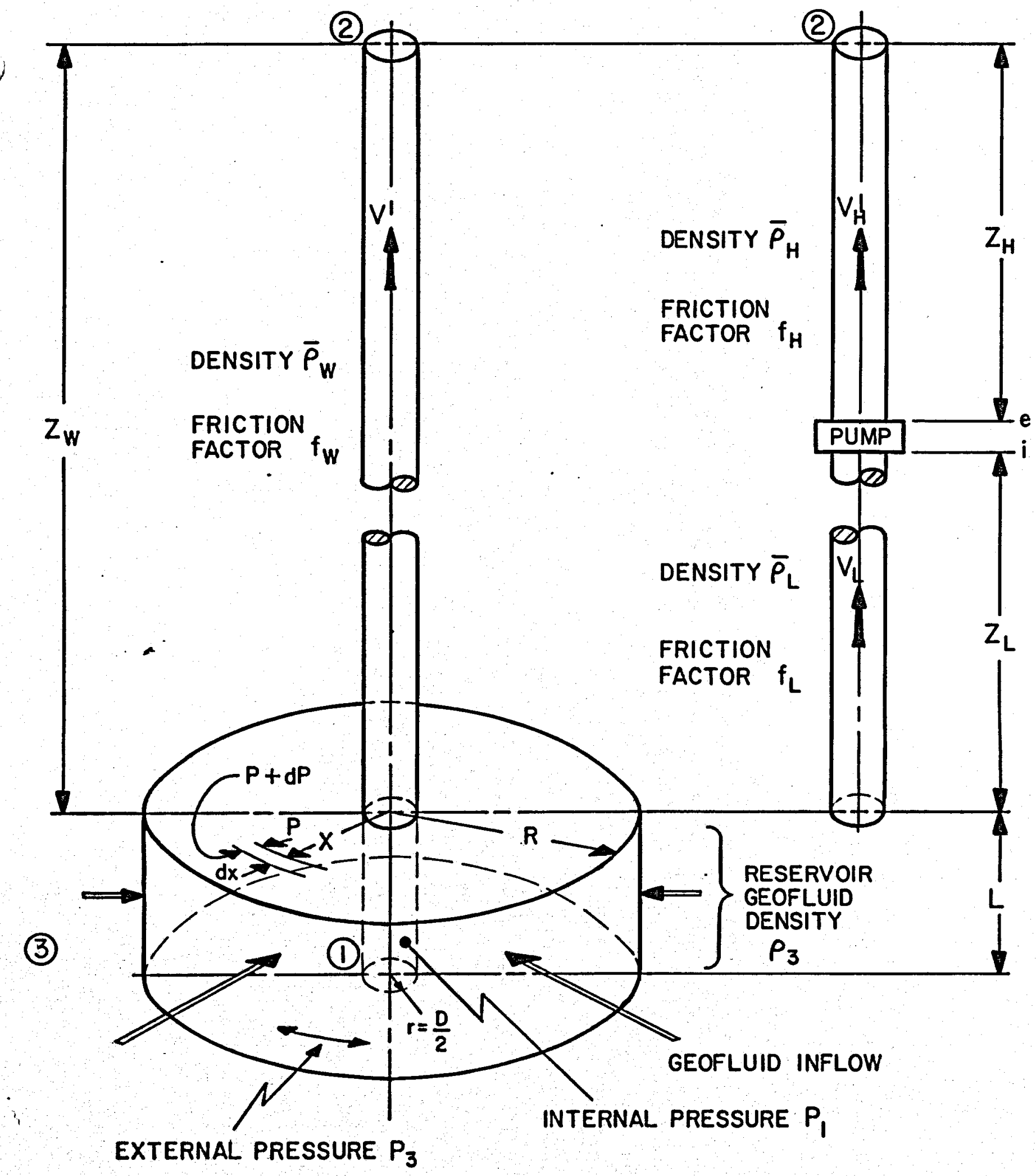

(a)

THE WELL AND ASSOCIATED RESERVOIR

(a) No pump

(b) Hell pumped

FIG. 5 


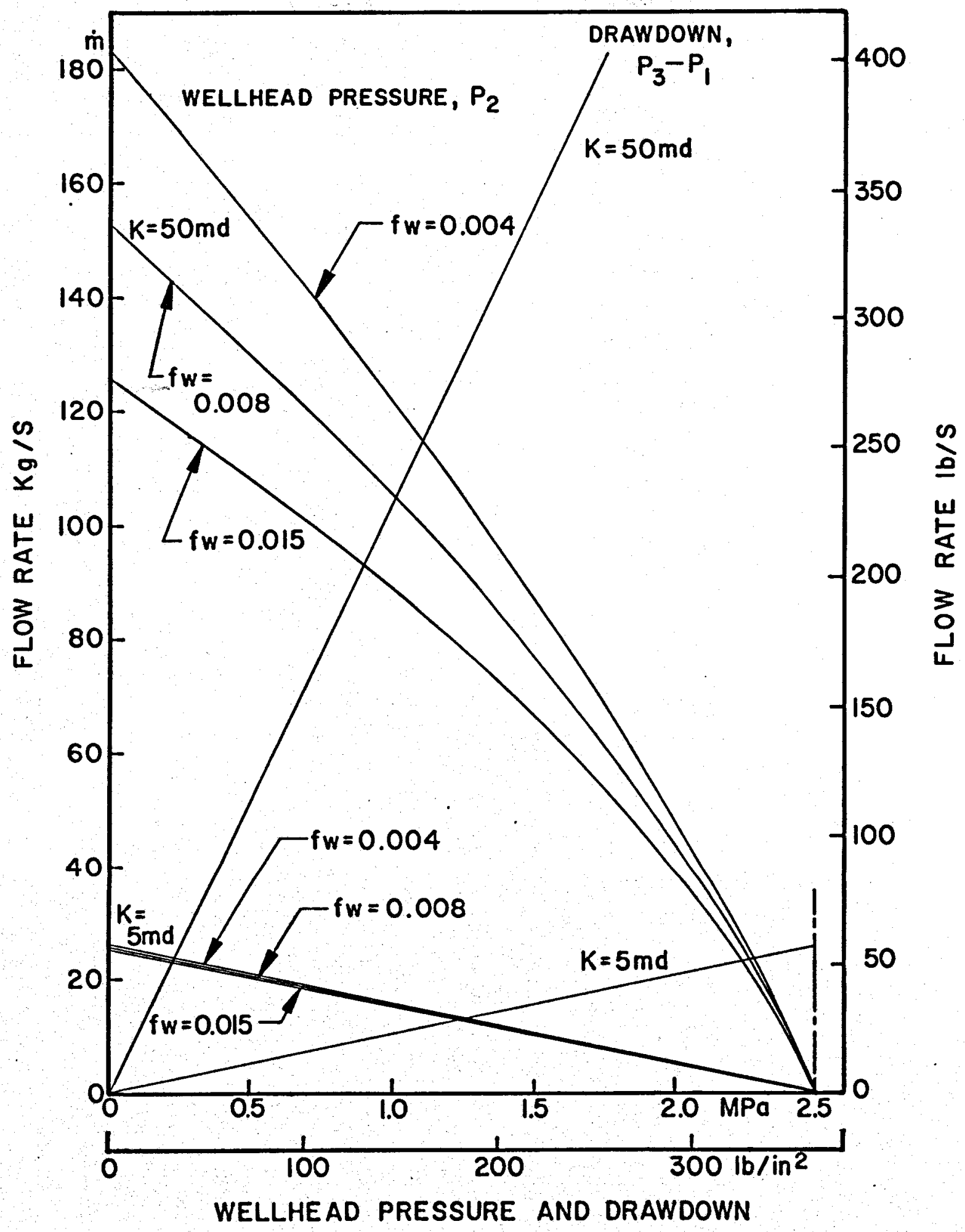

FLOW RATE, WELLHEAD PRESSURE AND DRAWDOWN FOR SELF-FLOWING WELL

FIG. 6 


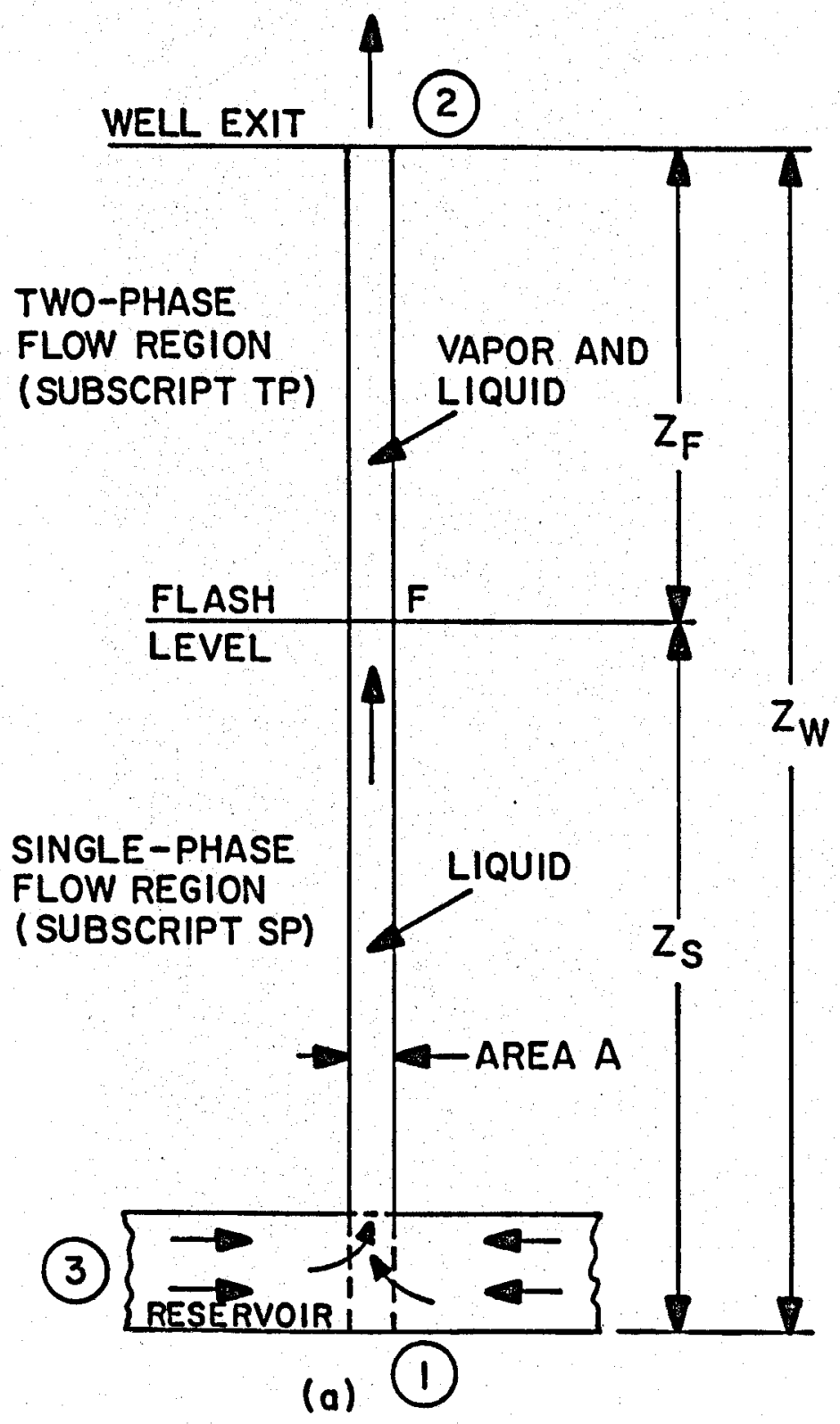

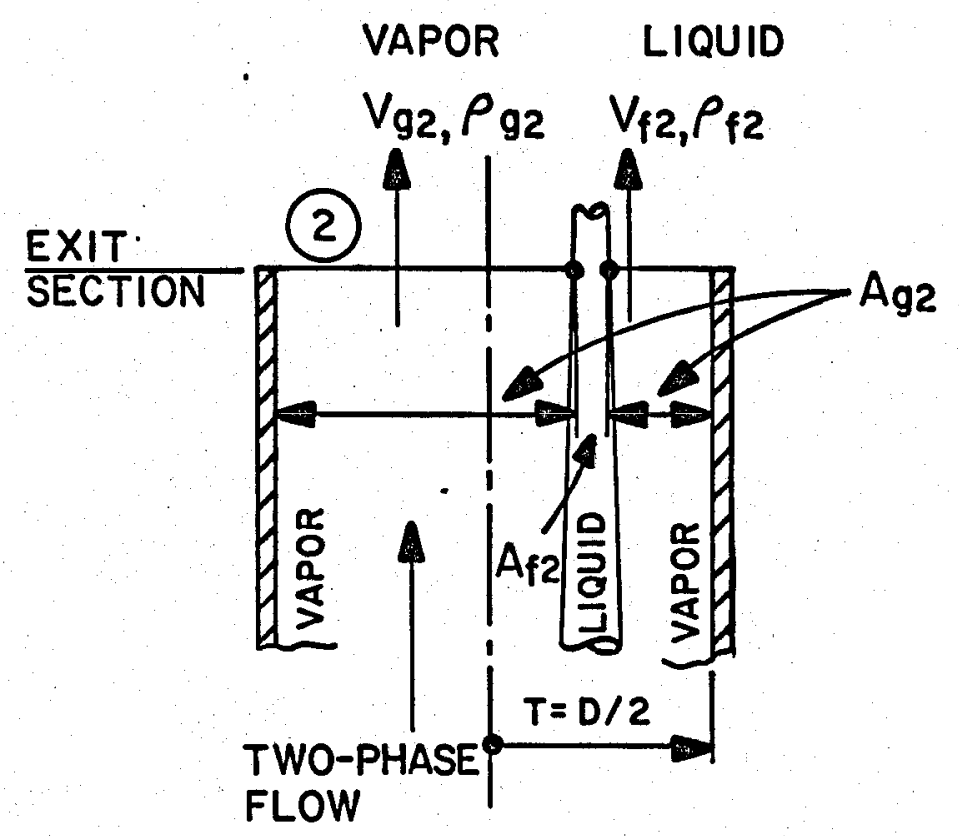

(b)
THE SELF-FLOWING FLASHING WELL

(a) Diagram showing general notation

(b) Notation at the wellhead where the equivalent filaments cross the well exit

FIG. 8 


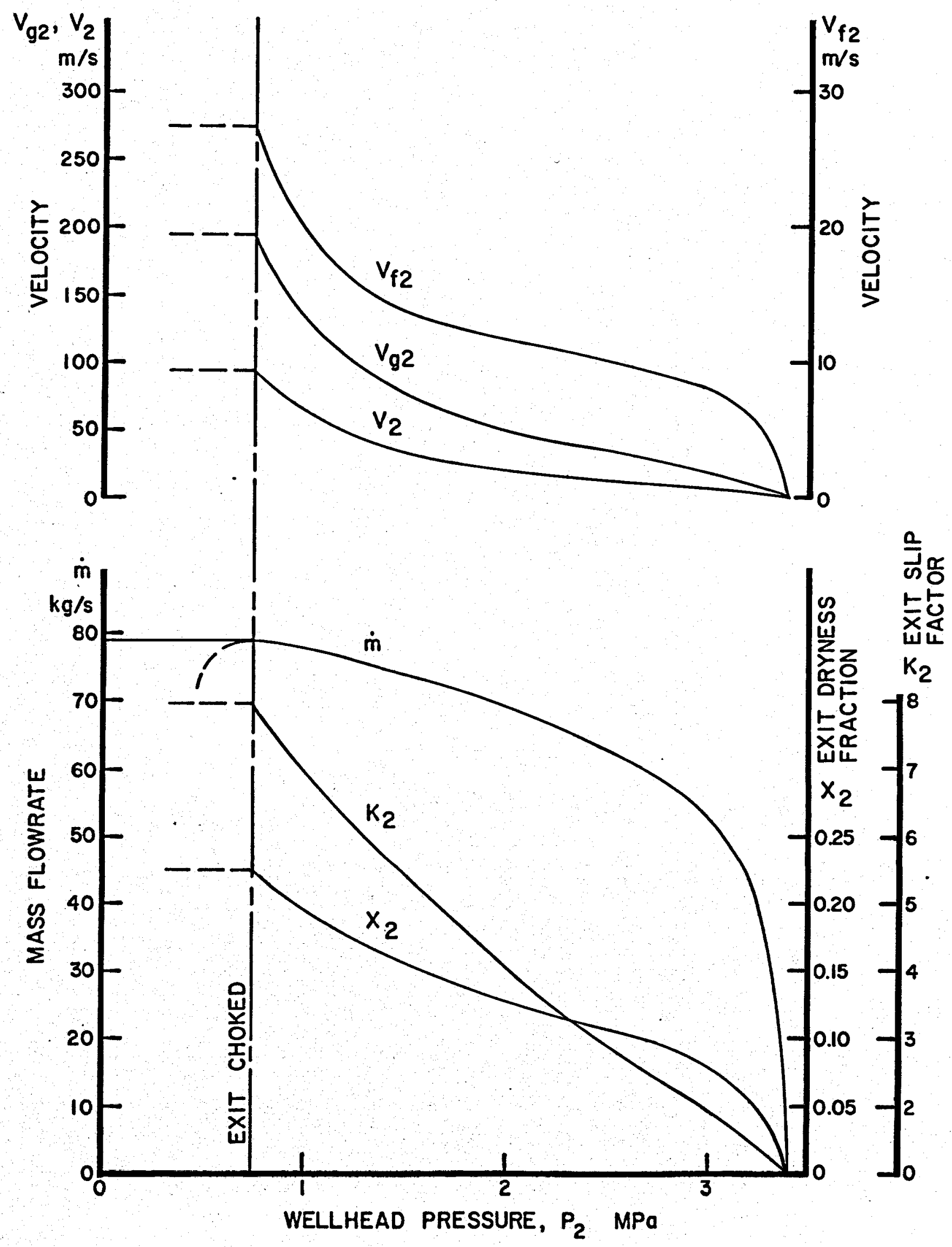

THE SELF-FLOWING FLASHING WELL: MISCELLANEOUS CURVES

FIG. 9 


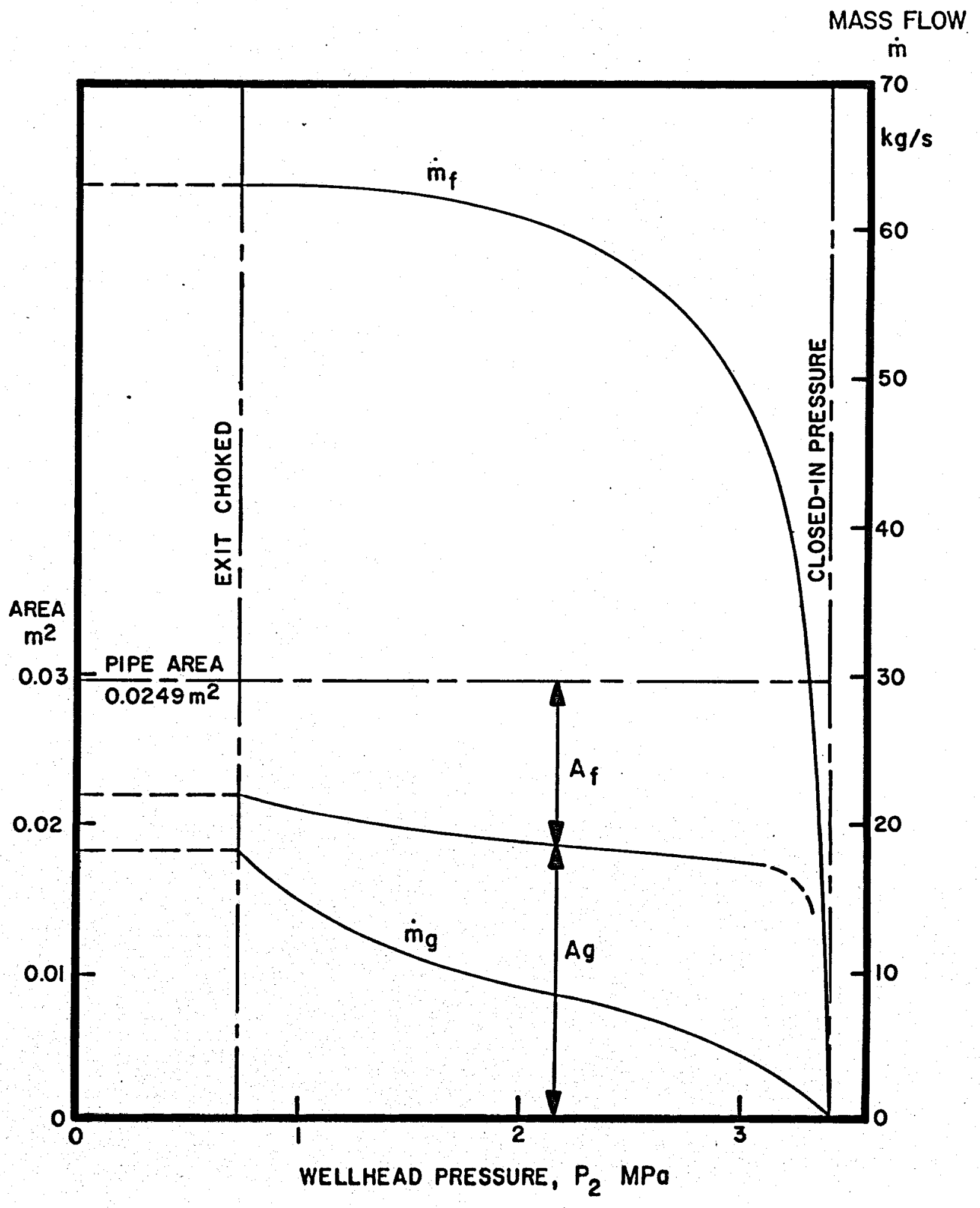

THE SELF-FLOWING FLASHING WELL: MISCELLANEOUS CURVES

FIG. 10 


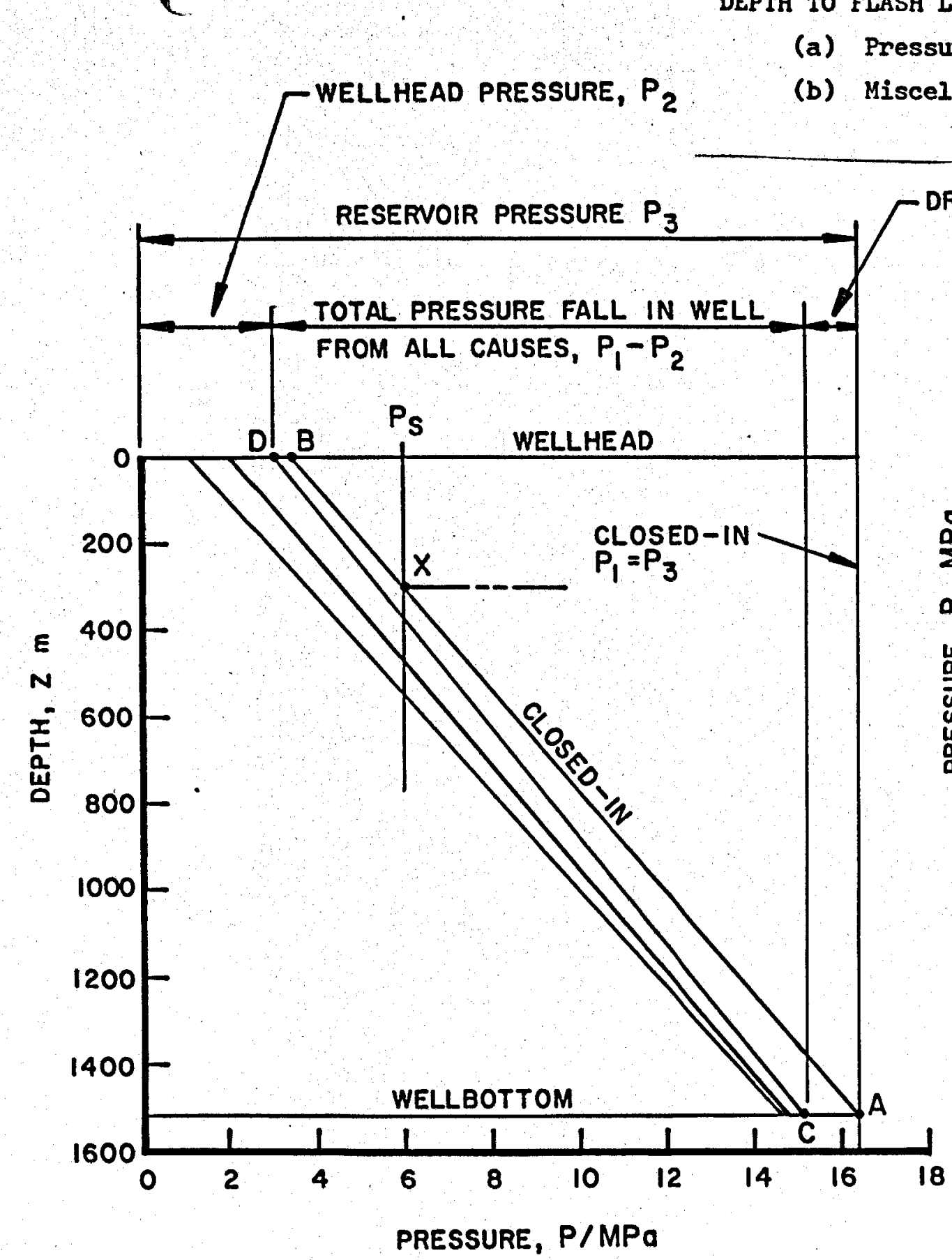

(a)

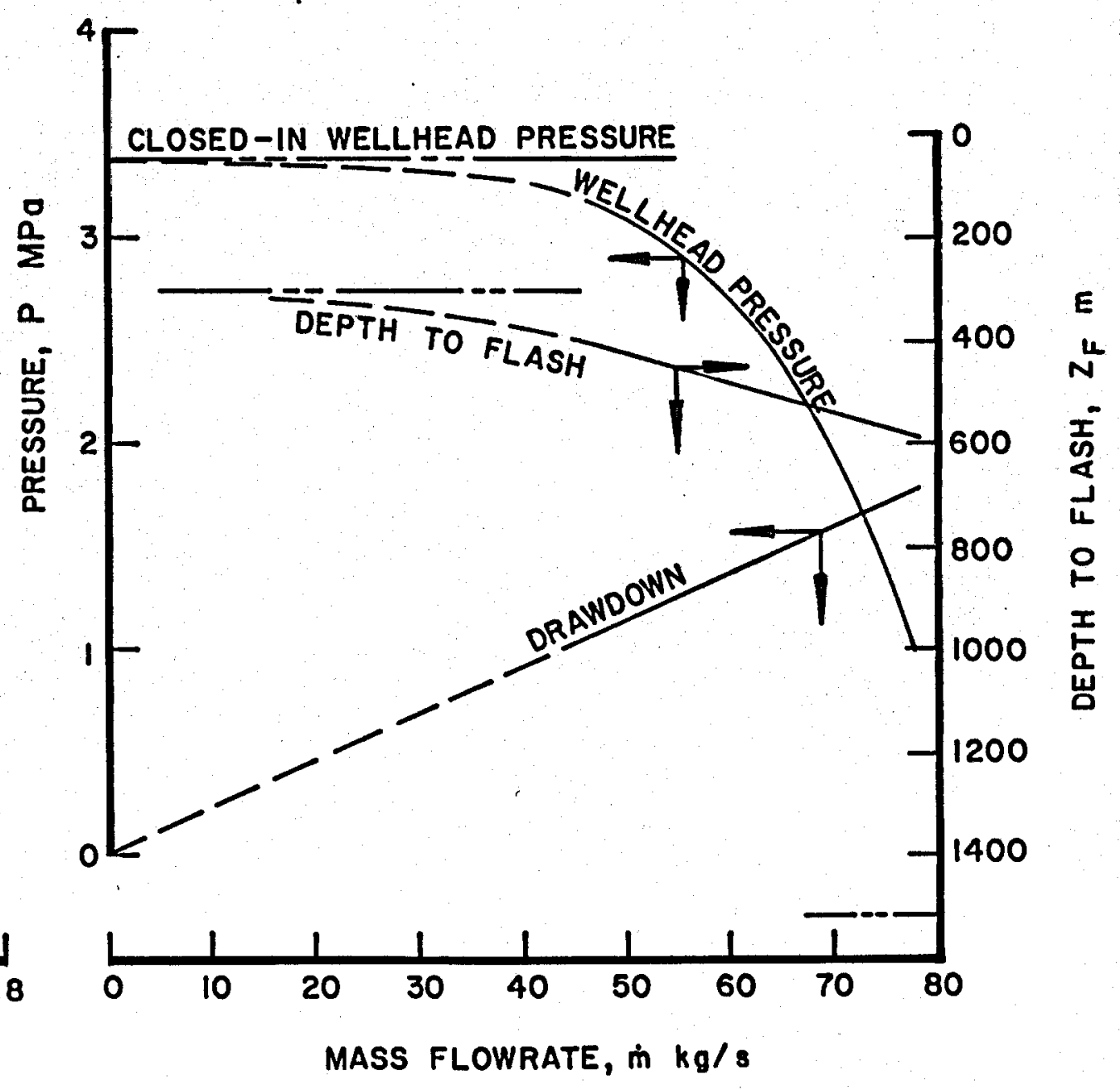

(b) 


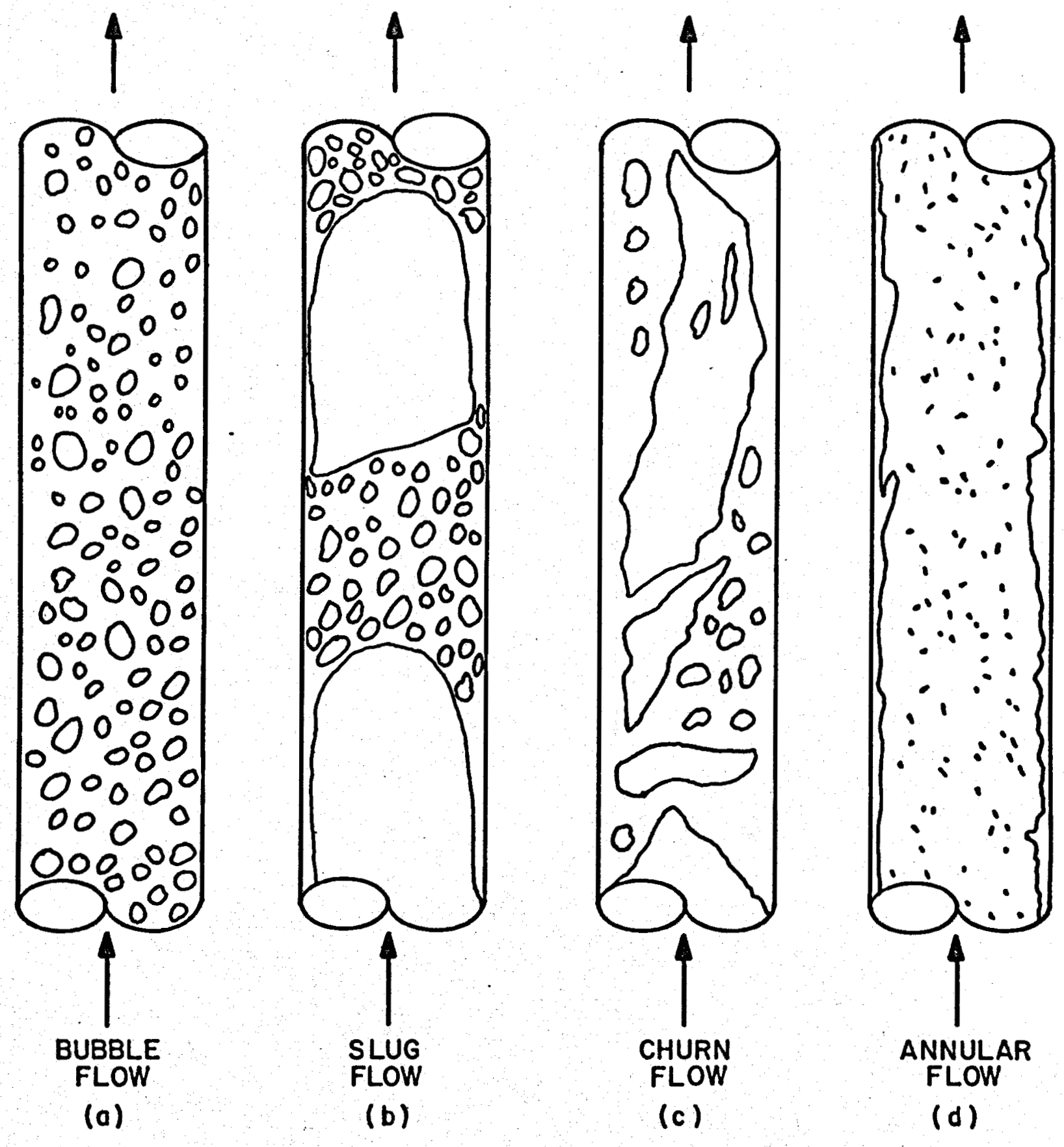

PRINCIPAL FLOW PATTERNS IN VERTICAL TWO-PHASE FLOW 


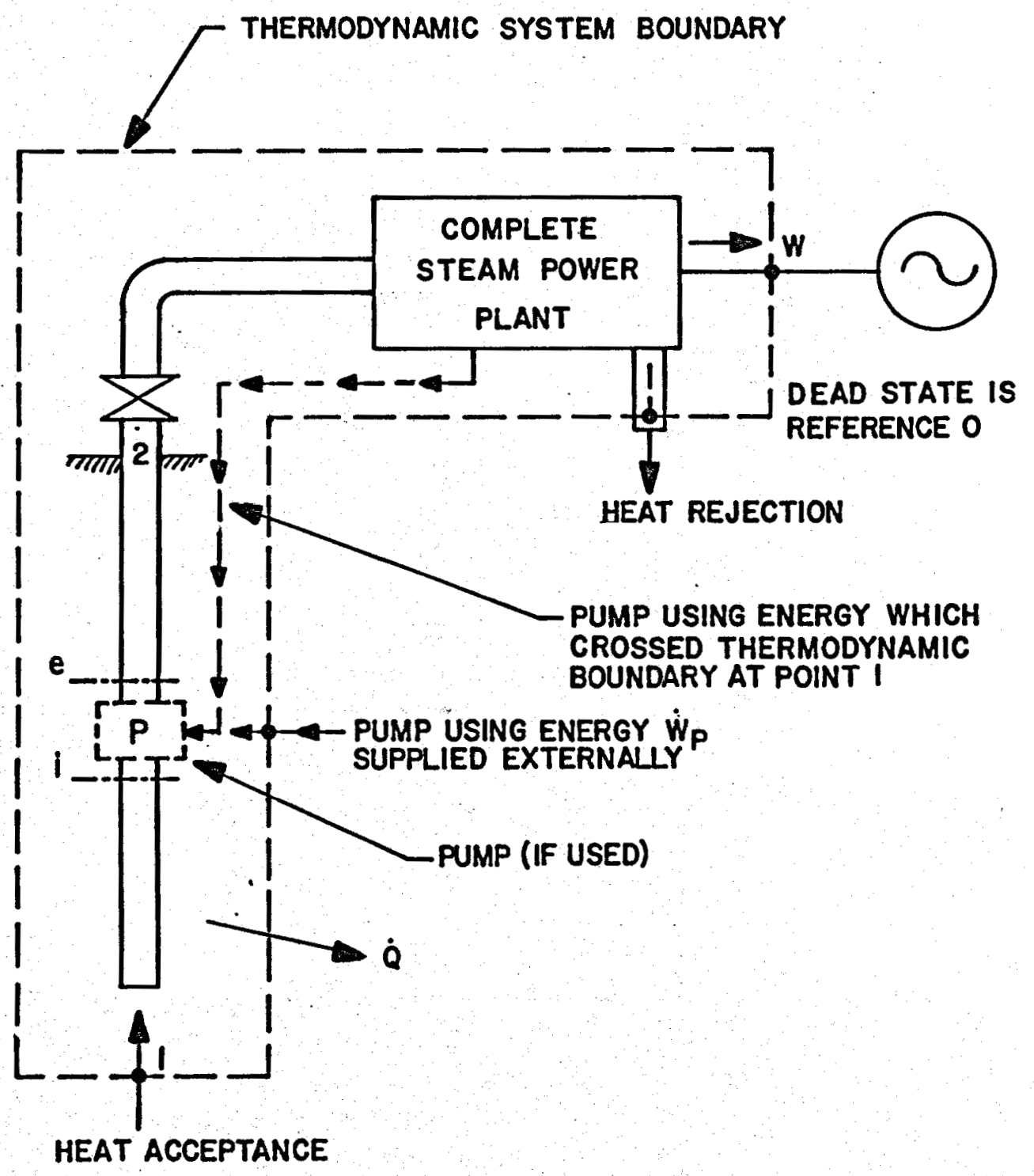

DIAGRAM FOR ILLUSTRATING THE CONCEPT OF AVAILABILITY FIG. 13 


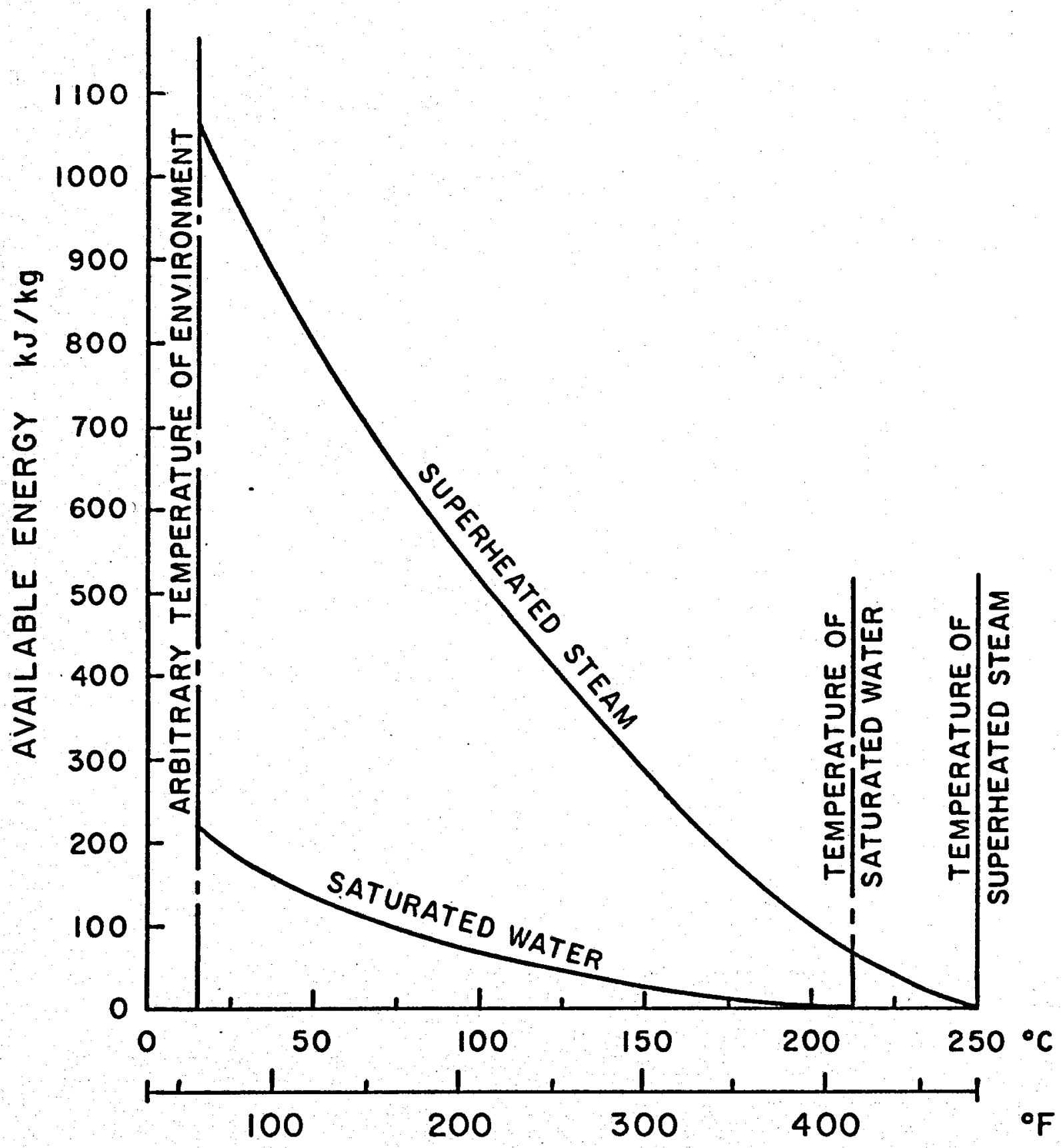

HEAT REJECTION TEMPERATURE FROM ENERGY CONVERSION DEVICE

CONDITIONS AT WELLHEAD

STEAM $2 \mathrm{MPO}, 250^{\circ} \mathrm{C}\left(290 \mathrm{lb} / \mathrm{in}^{2}\right.$ abs, $\left.482^{\circ} \mathrm{F}\right)$

WATER, SATURATED, $2 M P O\left(290 \mathrm{lb} / \mathrm{in}^{2}\right.$ abs $)$

VARIATION OF AVAILABLE ENERGY WITH HEAT REJECTION TEMPERATURE

FROM ENERGY SOURCES AT GIVEN INITIAL CONDITIONS

FIG. 14 